\title{
Effects of bubbles, cracks, and volcanic tephra on the spectral albedo of bare ice near the Transantarctic Mountains: Implications for sea glaciers on Snowball Earth
}

\author{
Ruzica Dadic, ${ }^{1}$ Peter C. Mullen, ${ }^{2}$ Martin Schneebeli, ${ }^{3}$ Richard E. Brandt, ${ }^{2,4}$ and \\ Stephen G. Warren ${ }^{2,5}$ \\ Received 10 January 2013; revised 13 June 2013; accepted 21 June 2013; published 5 September 2013.
}

[1] Spectral albedo was measured along a $6 \mathrm{~km}$ transect near the Allan Hills in East Antarctica. The transect traversed the sequence from new snow through old snow, firn, and white ice, to blue ice, showing a systematic progression of decreasing albedo at all wavelengths, as well as decreasing specific surface area (SSA) and increasing density. Broadband albedos under clear-sky range from 0.80 for snow to 0.57 for blue ice, and from 0.87 to 0.65 under cloud. Both air bubbles and cracks scatter sunlight; their contributions to SSA were determined by microcomputed tomography on core samples of the ice. Although albedo is governed primarily by the SSA (and secondarily by the shape) of bubbles or snow grains, albedo also correlates highly with porosity, which, as a proxy variable, would be easier for ice sheet models to predict than bubble sizes. Albedo parameterizations are therefore developed as a function of density for three broad wavelength bands commonly used in general circulation models: visible, near-infrared, and total solar. Relevance to Snowball Earth events derives from the likelihood that sublimation of equatorward-flowing sea glaciers during those events progressively exposed the same sequence of surface materials that we measured at Allan Hills, with our short $6 \mathrm{~km}$ transect representing a transect across many degrees of latitude on the Snowball ocean. At the equator of Snowball Earth, climate models predict thick ice, or thin ice, or open water, depending largely on their albedo parameterizations; our measured albedos appear to be within the range that favors ice hundreds of meters thick.

Citation: Dadic, R., P. C. Mullen, M. Schneebeli, R. E. Brandt, and S. G. Warren (2013), Effects of bubbles, cracks, and volcanic tephra on the spectral albedo of bare ice near the Transantarctic Mountains: Implications for sea glaciers on Snowball Earth, $J$. Geophys. Res. Earth Surf., 118, 1658-1676, doi:10.1002/jgrf.20098.

\section{Introduction}

[2] According to the Snowball Earth hypothesis, nearly the entire ocean was covered with thick ice during the early Paleoproterozoic (2.45-2.22 Ga ago) and the late Neoproterozoic (0.73-0.58 Ga ago) [e.g., Kirschvink, 1992; Kirschvink et al., 2000; Hoffman and Schrag, 2002]. Tropical glaciation would have been facilitated by a

\footnotetext{
${ }^{1}$ Antarctic Research Centre, Victoria University of Wellington, Wellington, New Zealand.

${ }^{2}$ Department of Atmospheric Sciences, University of Washington, Seattle, Washington, USA.

${ }^{3}$ WSL Institute for Snow and Avalanche Research, SLF, Davos, Switzerland.

${ }^{4}$ Atmospheric Sciences Research Center, State University of New York at Albany, Wilmington, New York, USA.

${ }^{5}$ Astrobiology Program, University of Washington, Seattle, Washington, USA.

Corresponding author: R. Dadic, Antarctic Research Centre, Victoria, University of Wellington, Wellington, New Zealand. (ruzica.dadic@vuw.ac.nz)
}

(C)2013. American Geophysical Union. All Rights Reserved. 2169-9003/13/10.1002/jgrf.20098 runaway albedo feedback of snow and ice that can occur when oceanic freezing reaches the subtropics [Budyko, 1969; Sellers, 1969].

[3] Despite the name, the Earth would not have been entirely snow-covered (Figure 1). The high- and midlatitude oceans would have been occupied by sea glaciers that were indeed snow-covered, with surface albedo about 0.8 . But in the tropics, with net sublimation and daytime air temperatures no higher than $-30^{\circ} \mathrm{C}$ [Pollard and Kasting, 2004; Pierrehumbert, 2005], much of the ice would not have been snow-covered and would have exhibited a variety of surfaces: bare sea ice, bare cold glacier ice, patchy snow, frost, salt, and dust.

[4] On the modern Earth snow and ice are mostly confined to high latitudes, where they receive little solar radiation. But if snow and ice reach low latitudes, they are exposed to intense solar radiation, so accurate values of snow and ice albedo are crucial to climate modeling of a snowball planet [Lewis et al., 2006]. In contrast to the global-warming problem for future climate change, where the biggest source of uncertainty is cloud feedback, in the snowball problem, the biggest source of uncertainty is surface albedo. 


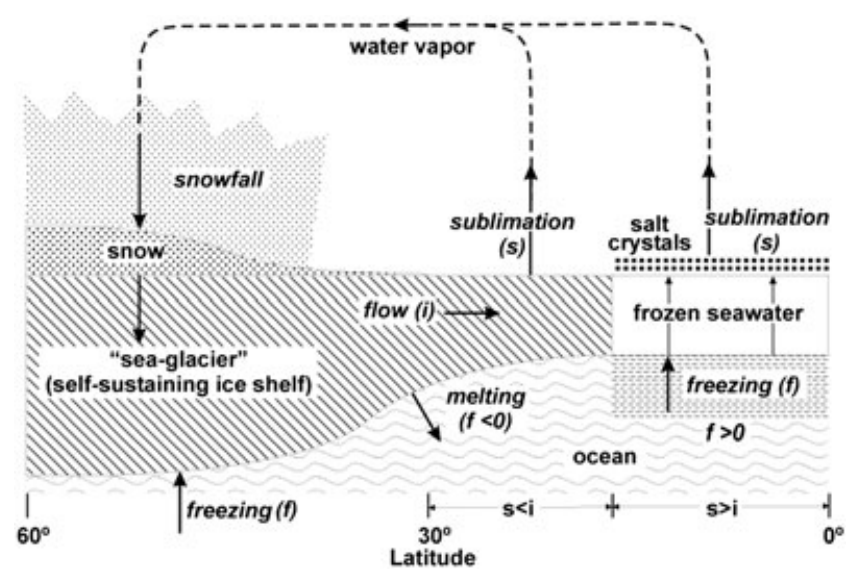

Figure 1. Schematic cross section of the upper ocean from $60^{\circ}$ latitude to the equator, showing processes that are important after the ocean has become completely ice-covered and the ice has reached equilibrium thickness. Freshwater ice that formed in middle and high latitudes, originating as snowfall, flows equatorward under its own weight as a "sea glacier." Over the tropical ocean, the sublimation rate exceeds the snowfall rate; the net sea glacier inflow $(i)$ is balanced by the net ablation of ice at the upper surface $(s)$ and by melting at the lower surface. If $s>i$, as expected at the onset of tropical glaciation, there is freezing (f) at the base, and the resulting throughput of frozen seawater leaves sea salt behind at the upper surface. If $s<i$, the expected situation for the entire low-latitude region for most of the time during a snowball event, the sea glacier will advance to the Equator, and melting rather than freezing will occur at the base at low latitudes.

Pierrehumbert et al. [2011] showed that a change of ice albedo from 0.55 to 0.65 means a factor-of- 10 increase in the $\mathrm{CO}_{2}$ mixing ratio required to end the snowball state. They commented: "The results shown in Figure 3 highlight the extreme sensitivity of the initiation and deglaciation thresholds to albedo .... A small change of albedo ... requires a very large change of $\mathrm{CO}_{2}$ to make up for it." Climate models of Snowball Earth have varied greatly in the albedos they specify for tropical bare ice [Pierrehumbert et al., 2011, Table 3], so putting observational constraints on the allowed albedos will improve the realism of these models. For example, the "Jormungand" state (exhibiting a narrow belt of open water along the equator) can exist with sea glacier albedo of 0.45 but is inaccessible for sea glacier albedo greater than about 0.55 [Abbot et al., 2011, Figure 12]. The albedo also determines whether thin ice can exist on the tropical ocean. Warren et al. [2002] showed that an albedo change of 0.1 could change the equilibrium ice thickness from 1 to $700 \mathrm{~m}$. Indeed, in a model coupling a general circulation model (GCM) with a sea glacier flow model, increasing the albedo from 0.47 to 0.64 caused the equatorial ice thickness to increase from 1 to $1000 \mathrm{~m}$ [Pollard and Kasting, 2005; Warren and Brandt, 2006].

[5] The ice type covering the greatest area of the tropical sublimation zone for the longest time is likely to be bare cold glacier ice, as explained below in section 8 . The only modern examples of glacier ice exposed by sublimation, which has never experienced melting, are the "blue ice" surfaces of the Antarctic Ice Sheet near the Trans-Antarctic Mountains (Figure 2). Pure ice is blue, but because of the high bubble content in sublimating glacier ice, it would be better described as "blue-white." The number density and size distribution of these bubbles determine the albedo of the ice [Bohren, 1983; Warren et al., 1993]. The broadband albedos of Antarctic blue ice have been measured as 0.55-0.65 in Queen Maud Land [Bintanja and van den Broeke, 1995; Bintanja, 1999; Liston et al., 1999; Reijmer et al., 2001], 0.63 in the Transantarctic Mountains [Warren et al., 1993, 2002], and 0.66 at Mawson Station on the coast of East Antarctica [Weller, 1968]. The lowest reported albedo, 0.55, was for ice at low elevation $(1100 \mathrm{~m})$, so it may have experienced melting at or near the surface [Bintanja, 1999; Liston and Winther, 2005].

[6] Because of the sensitivity of equatorial ice thickness to the albedo and transmissivity of the ice [Warren et al., 2002], it is important to determine the variability of bubble content and albedo of Antarctic blue ice, and the causes of variability. The bubbles closeoff at a firn density of about $830 \mathrm{~kg} \mathrm{~m}^{-3}$, which can be reached in just 100 years in a location with heavy snowfall but may take 3000 years in the low-accumulation regions of the East Antarctic Ridge. The bubbles occur at junctions of three or more grains, so their number depends on the average grain size at the close-off depth [Gow, 1970; Alley et al., 1986]. The initial grain size depends on temperature, as does the accumulation rate. The grain size of the largest grains increases with time at a rate determined by temperature [Gow, 1969], but the number-average grain size does not [Kipfstuhl et al., 2009]. The area-weighted average grain size, which is the most relevant measure for determining bubble specific surface area (SSA), would be intermediate between these two results. Although higher temperature should mean larger bubbles, the time to closeoff is shorter because of the higher accumulation rate at higher temperature. These counteract-

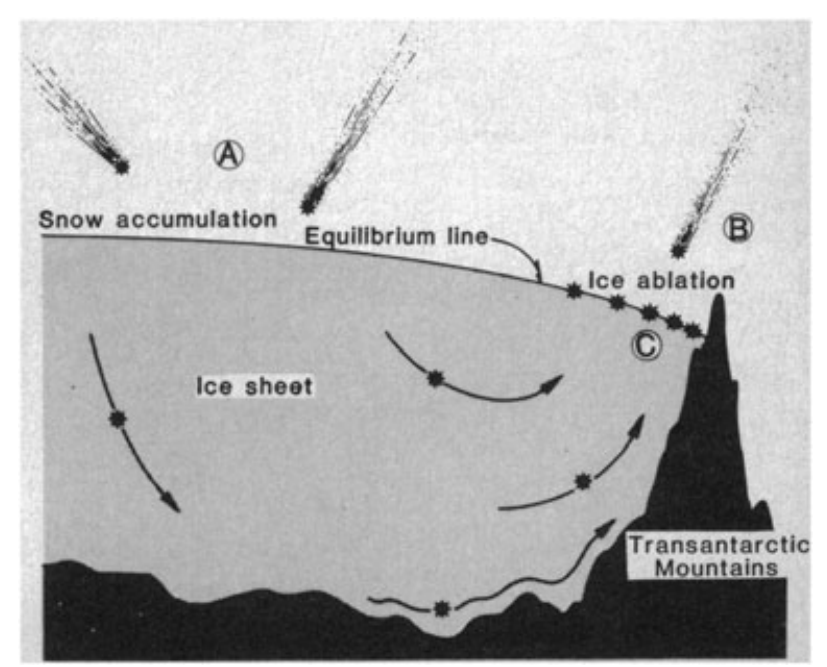

Figure 2. Ice flow in the region of the Allan Hills, indicating how meteorites are accumulated. Below the equilibrium line, the sequence of surfaces is old snow (firn), young white ice, and old blue ice. From Whillans and Cassidy [1983, Figure 1], reprinted by permission from American Association for the Advancement of Science. 


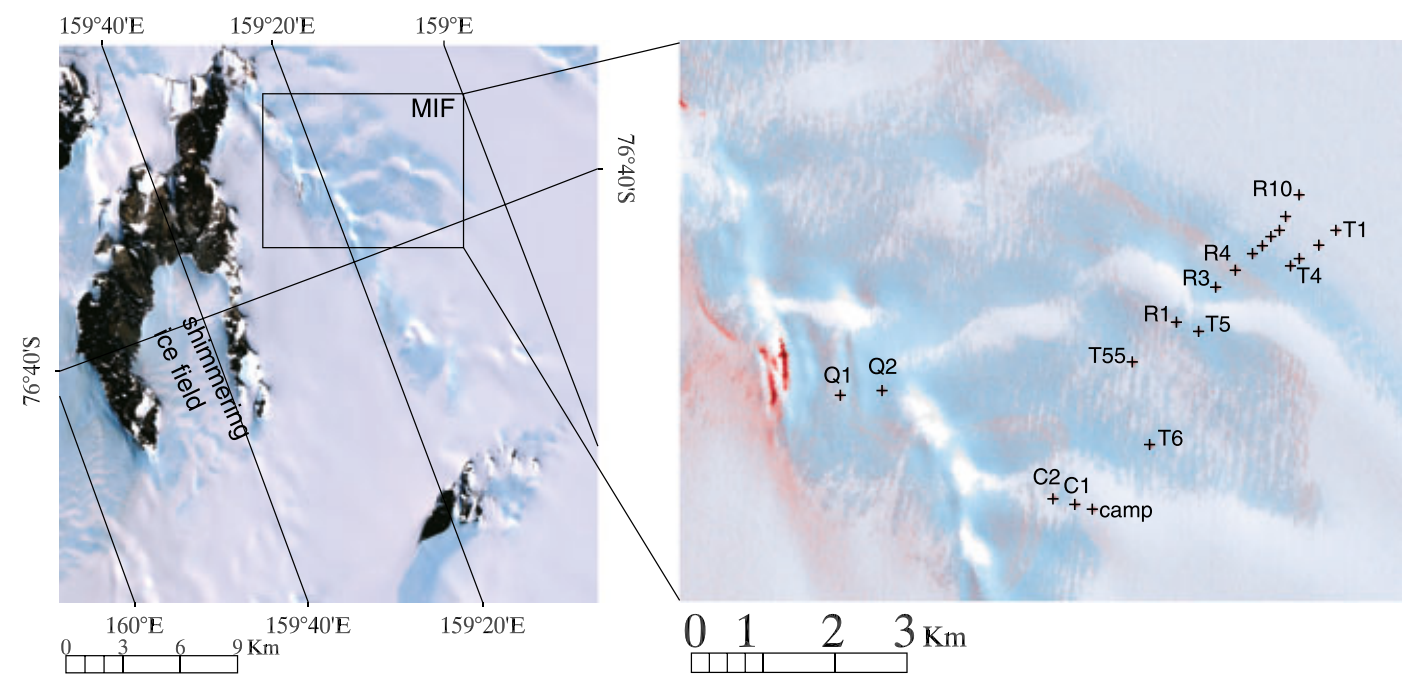

Figure 3. Allan Hills, Antarctica from Landsat Mosaic of Antarctica [Bindschadler et al., 2008]. The inset zooms on the Main Ice Field (MIF), where the crosses indicate our measurements sites. The reddish color is either glacial sediment (lower left of image) or ash layers (where it intersects blue ice).

ing influences may conspire to keep bubble size at closeoff relatively independent of surface temperature.

[7] Bubbles in glacier ice have been discussed in the context of ice cores and paleoclimates [e.g., Gow, 1970; Alley et al., 1986; Lipenkov, 2000]. Extracted from depths of tens to hundreds of meters and therefore not relevant for radiative transfer, ice from deep cores has not been discussed in the context of albedo. It is also not clear how bubble size distribution from deep ice cores may represent the ice in the blue ice in the Allan Hills, which has likely been exposed to pressures so great that each air bubble became dissolved in the ice to form a clathrate crystal [Price, 1995], and then reformed as the pressure was released [Lipenkov, 2000].

[8] While there are many studies that have discussed the direct link between microstructure and albedo in snow [Wiscombe and Warren, 1980; Warren, 1982; Grenfell and Warren, 1999; Painter and Dozier, 2004; Flanner and Zender, 2006; Haussener et al., 2012], only Mullen and Warren [1988] have discussed the direct link between ice albedo and the bubble size distribution in freshwater ice, adapting theories for sea ice albedo and snow albedo. They found that the spectral albedo is dominated by the specular reflection of the flat ice surface in the near-infrared and by multiple scattering of bubbles in the visible wavelengths. They concluded that the spectral albedo of lake ice depends on the bubble size distribution and that ice density is a poor predictor of albedo. The size distribution of bubbles can be described as a combination of an effective bubble concentration and effective bubble radius. These can be related to the specific surface area (area-to-mass ratio) [Haussener et al., 2012].

[9] The Antarctic blue ice areas have been well-mapped because of their importance in the search for meteorites [Cassidy et al., 1992]. A transect across an ice field will sample ice of different ages that has traveled to different depths en route to the sublimation front (Figure 2). Some of the blue ice at the surface in Allan Hills may be several million years old [Harvey et al., 1998]. The albedo-transition from snow to firn to ice can be measured at the edge of the blue ice areas, mimicking the equatorward evolution of a sea glacier surface. Parameterization of this transition turned out to be a critical source of uncertainty as to whether sea glaciers would reach the equator [Pollard and Kasting, 2005].

[10] The aim of this paper is to understand the ice and firn microstructure in blue ice areas and the effects the microstructure, and air bubbles in particular, have on albedo, and how well blue ice areas might represent the albedos on the tropical ocean of Snowball Earth. On a $6 \mathrm{~km}$ transect from snow to ice near the Allan Hills, we measured spectral albedo and collected $1 \mathrm{~m}$ core samples. The measured spectral albedos are integrated over wavelength and weighted by the spectral solar flux to obtain broadband albedos. We use microcomputed tomography (micro-CT) to analyze the microstructure of ice and firn and to obtain SSA. We also melted and filtered some cores to determine the spectral absorption of volcanic ash, which was present in varying amounts in the ice. The SSA and the spectral absorption of ash are both used to constrain radiative transfer modeling, which is then compared to measured spectral albedos. Because the sublimation rate is only $3-5 \mathrm{~cm} / \mathrm{yr}$, the ice surface in the Allan Hills is exposed to strong seasonal temperature variations, which leads to thermal expansion and contraction of ice which results in cracking. We quantify the effects of cracks on the albedo using images of the surface and stereology, in combination with micro-CT evaluation of the SSA within individual cracks.

[11] Our results show that the broadband albedo is well-correlated to porosity, which as a proxy would be easier to predict than SSA in an ice sheet model, using a firn-densification function. We use that correlation to develop albedo parameterizations as a function of density for broad wavelength bands commonly used in GCMs: visible, near-infrared, and total solar.

[12] We then discuss the relevance of our study to Snowball Earth, how the albedo in the present-day Allan Hills might differ from the albedo over a tropical Snowball Ocean, and what our results mean for the thickness of sea glaciers during the Neoproterozoic. 


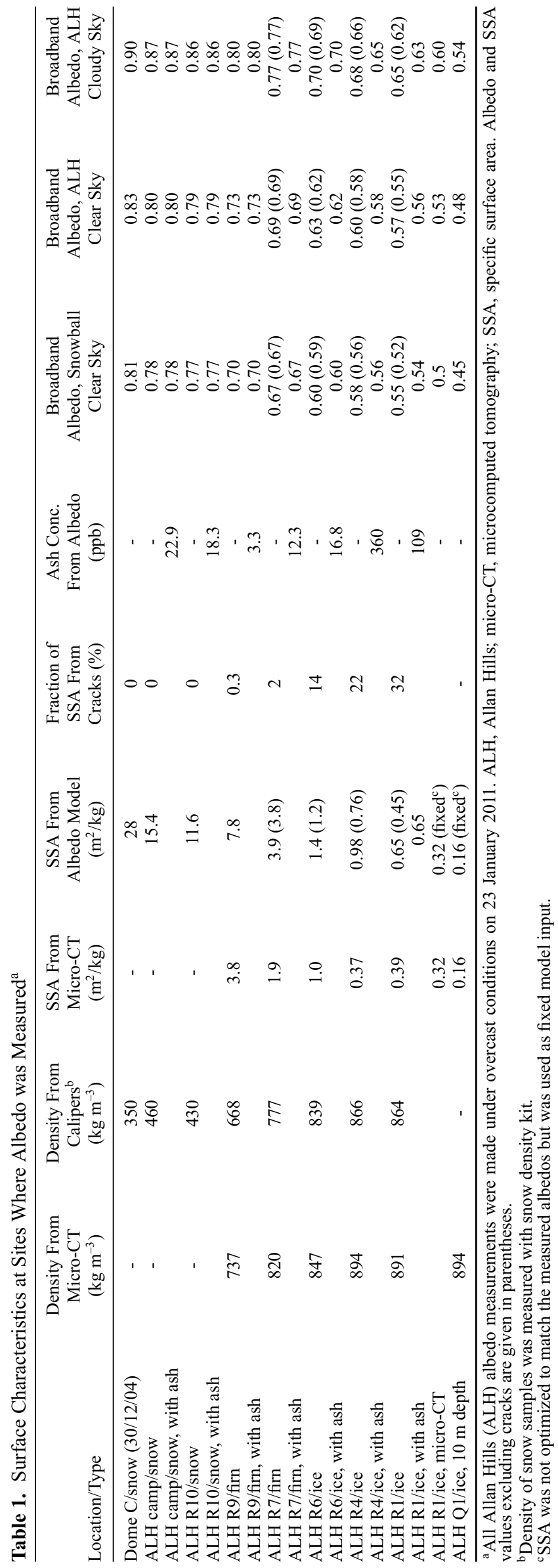

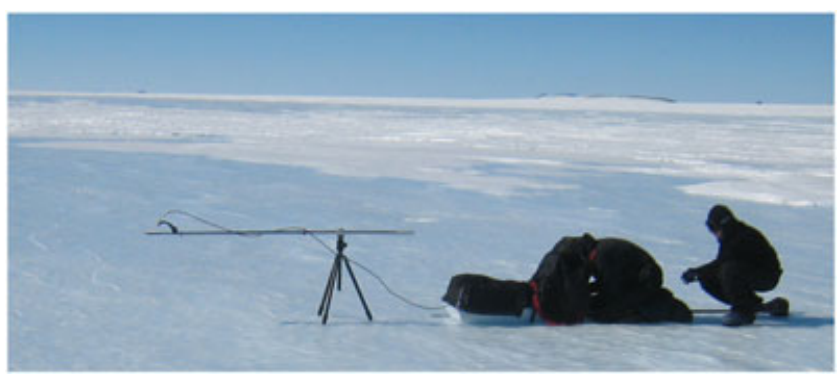

Figure 4. Albedo measurement over blue ice. The fiberoptic cable is mounted at the end of a long rod, so the field of view has minimal contribution from the tripod and sled.

\section{Field Data Collection}

[13] During December 2010 and January 2011, we carried out a field campaign, based at a tent camp near the Allan Hills $\left(76.67^{\circ} \mathrm{S}, 159.23^{\circ} \mathrm{E}, 2000 \mathrm{~m}\right.$ elevation). The field camp was accessed by a Twin Otter ski plane from McMurdo Station. We measured spectral albedo and collected core samples ( $1 \mathrm{~m}$ long, $90 \mathrm{~mm}$ diameter) of the ice along two transects from the edge to the center of a blue ice area (Figure 3). Surfaces on the transects transitioned through the sequence new snow-old snow-firn-young white ice-old blue ice. The ice flow in this region (the Main Ice Field, just west of the Allan Hills) has been studied previously in connection with searches for meteorites or ice cores and paleoclimate [Nishio et al., 1982; Spaulding et al., 2012].

[14] The core samples were taken at the locations of the albedo measurements and were studied later in the laboratory with the aim of explaining the albedo measurements. Some characteristics of the sites that received the most attention in our analyses are given in Table 1.

\subsection{Spectral Albedo Measurements}

[15] Spectral albedo was measured using a FieldSpec Pro JR spectral radiometer from Analytical Spectral Devices, Inc. (ASD). The instrument employs three separate grating spectrometers that simultaneously measure radiance across three wavelength regions covering 350-2500 nm, with spectral resolution 3-10 $\mathrm{nm}$, and can average 100 scans in $10 \mathrm{~s}$ [Kindel et al., 2001]. It is designed specifically to cover the solar spectrum and has order-blocking and cutoff filters to ensure uncontaminated spectra. We had used this instrument previously to measure snow albedo, snow transmittance, and bidirectional reflectance at Dome C on the East Antarctic Plateau [Hudson et al., 2006; Warren et al., 2006]. A Spectralon diffuser-plate receptor is used for measurement of albedo. The ASD radiometer and its computer are both battery-powered and housed in separate insulated boxes. At ambient temperatures of $-20^{\circ} \mathrm{C}$ to $-35^{\circ} \mathrm{C}$, the electronics were kept warm by self-heating supplemented by battery-powered heaters.

[16] For albedo measurements, the diffuser plate is mounted on a rod suspended $70 \mathrm{~cm}$ above the ice, supported at one end by a tripod resting on the ice (Figure 4). At each site, we alternately measured the downwelling and upwelling radiation 10 times. We then interpolated the time and spectral flux for the five downwelling measurements 


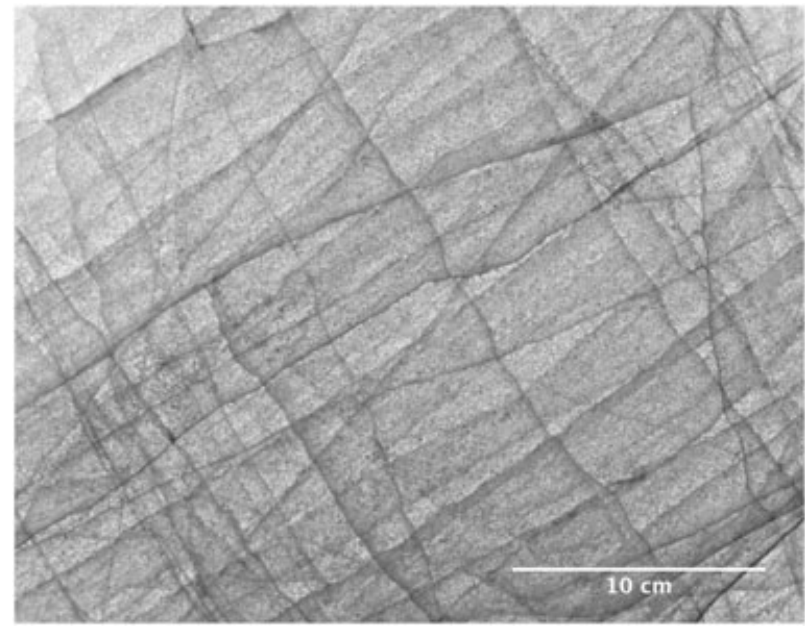

Figure 5. Picture of cracked ice at site T55. The pictures were used to estimate the area of crack planes within a volume of ice using stereology.

to get the downwelling radiation at the exact time that the upwelling radiation was measured, for use to calculate four spectral albedos at each site. Throughout this study, we show the average of those four albedos. The spectrally averaged standard deviation of the four spectral albedos measurements is less than 0.005 for all sites (for wavelengths $0.5-1.8 \mu \mathrm{m}$ ) and thus negligible for our purposes.

[17] Brandt et al. [2011] estimated the shadowing correction by geometric analysis to be $1.7 \%$ for this particular setup for diffuse incidence, and we therefore multiply the albedo at each wavelength by 1.017.

[18] We measured albedos under both clear-sky and overcast cloud. The overcast albedos are the most accurate, because errors due to slight slopes of the surfaces, tilt of the diffuser plate, and deviations from cosine response of the diffuser plate are minimized. All albedo measurements discussed in this paper were made under overcast cloud cover of sufficient optical thickness to produce a diffuse radiation field. Broadband albedo values for clear-sky conditions are obtained by weighting the measured spectral albedo by a modeled incident solar spectrum for clear sky.

\subsection{Shallow Cores}

[19] The cores were used for morphological analysis with microcomputed tomography (micro-CT). Some cores were melted and filtered to determine the spectral absorption of volcanic ash, which was present in varying amounts in the ice. We also analyzed ice from $10 \mathrm{~m}$ depth, which was cored in the same area during our field campaign by A. Kurbatov and his group (Climate Change Institute, University of Maine). We used this core as a reference for bubble size and shape that was not influenced by diurnal and seasonal temperature variations.

[20] At the field camp, the cores were stored in a snow drift at temperatures of $-20^{\circ} \mathrm{C}$ to $-30^{\circ} \mathrm{C}$. They were transported to McMurdo Station by a short Twin Otter flight, then stored in the Crary Laboratory cold room at $-30^{\circ} \mathrm{C}$. The cores were packed in dry ice before being shipped to the Snow and Avalanche Institute (SLF) in Davos, Switzerland, and to the University of Washington (UW) in the U.S. The samples were kept at $-60^{\circ} \mathrm{C}$ during transport, at $-20^{\circ} \mathrm{C}$ at the $\mathrm{SLF}$, and at $-15^{\circ} \mathrm{C}$ at the UW. The core samples at SLF were imaged by micro-CT in April-May 2011. The core samples at UW were used only for analysis of ash; they were melted and filtered at UW in March 2012.

[21] The seasonal temperature variations in the Allan Hills cause thermal expansion and contraction which results in cracking of the ice down to a depth of $\sim 4-5 \mathrm{~m}$. The cracks are visible in the ice and are likely to have an effect on the albedo. To quantify the amount of crack surfaces in the ice using stereology, we recorded 10 randomly oriented images of the surface at each site (e.g., Figure 5). Each picture was taken with a digital camera that was mounted over a circular hole that fitted the camera lens and that was cut into a cardboard box. This ensured that all pictures represent areas of the same size.

\section{Measured Spectral Albedos}

[22] Figure 6 shows albedo spectra from 350 to $1800 \mathrm{~nm}$. Beyond $1800 \mathrm{~nm}$, the data are noisy because of low light intensity. The curves are labeled by the density of the top $10 \mathrm{~cm}$. The top curve is for dense wind-packed snow, with density measured using a Taylor-LaChapelle snow density kit. The other four densities were estimated by weighing cylindrical sections of the cores whose dimensions had been measured by calipers as discussed below. In order of increasing density, the albedo curves are for snow, firn, white ice, blue ice, along the " $\mathrm{R}$ " transect in Figure 3. The transect from snow to ice shows a systematic progression of decreasing albedo at all wavelengths.

[23] We will attempt to explain these spectra in section 6 below, with absorption determined by the spectral absorption coefficient of pure ice and scattering determined by the surface area of bubbles and cracks. The downturn of albedo toward the ultraviolet (UV) indicates the presence

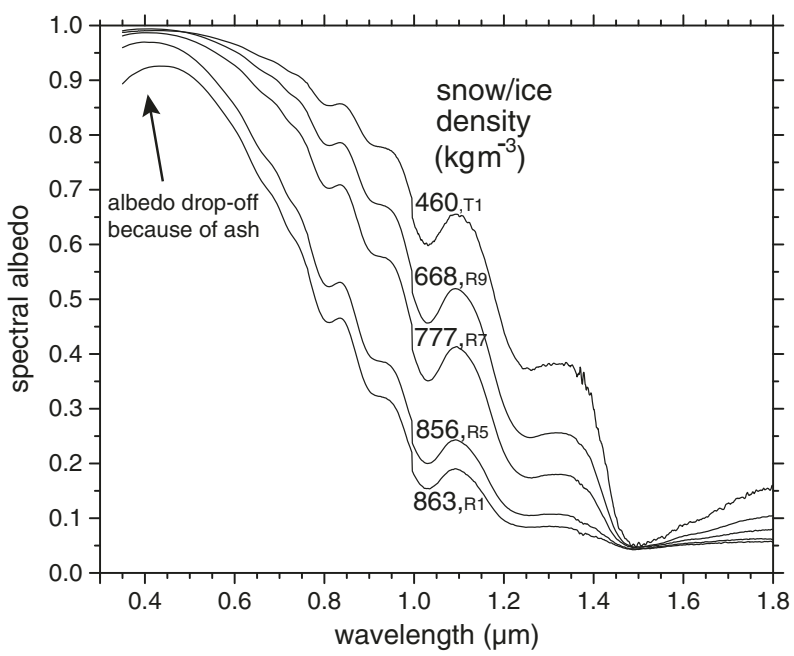

Figure 6. Spectral albedo measurements on the R-transect in Figure 3, from the accumulation zone into the ablation zone of the Allan Hills blue ice region, 23 January 2011. From top to bottom, the curves are in sequence along the transect: snow, firn, white ice, blue ice, and blue ice again. The density of the top $10 \mathrm{~cm}$ of the core is indicated. 

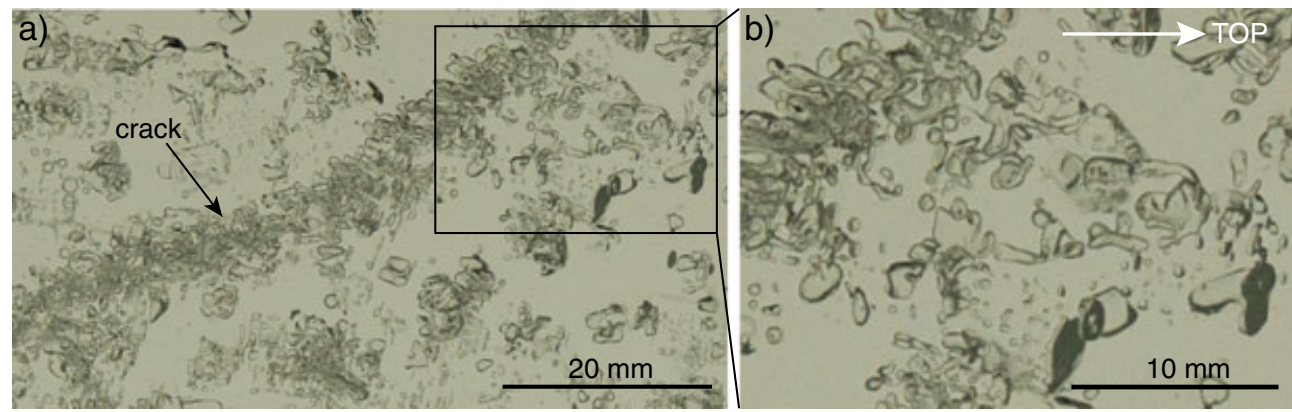

Figure 7. (a) Thick section of ice at location R5. (b) The zoom of the black box in Figure7a. Top of the core is to the right.

of another absorber besides ice, most likely volcanic ash, whose absorption spectrum we determine below in section 5 .

[24] The spectral albedos are integrated over wavelength, weighted by the spectral solar flux, to obtain broadband albedos as described below in section 7 . The broadband albedos under clear sky range from 0.80 for snow to 0.57 for blue ice; under cloudy sky from 0.87 for snow to 0.65 for blue ice (Table 1).

\section{Physical Properties of Snow, Firn, and Ice}

[25] We used the shallow cores to determine physical properties of the samples, in particular density and specific surface area (SSA; ratio of air-ice interface area to ice mass). Most of the evaluation was done using micro-CT, but we also made preliminary measurements of density using a caliper and a scale in the Crary laboratory at McMurdo Station, where we also photographed thick sections of each sample on a light table (Figure 7) to get a first indication of the ice morphology. The crack images (Figure 5) were used to determine the planar area of the cracks in the ice using stereology and to estimate the increase of the SSA due to cracks, because it is unlikely that our relatively small cores can capture the cracks (and the bubbles therein) sufficiently.

\subsection{Physical Properties and Morphology of Ice and Firn Using Microcomputed Tomography}

[26] The micro-CT method is described by Stock [2009]. The ice samples for the micro-CT were first cored to a diameter of $36 \mathrm{~mm}$ using a plug cutter. Imaging was done using a micro-CT 40 (Scanco Medical) computer tomograph. The field of view was $37 \mathrm{~mm}$, the effective voxel size $18 \mu \mathrm{m}$, the peak X-ray energy $55 \mathrm{kV}$, the intensity $145 \mu \mathrm{A}$, and the shutter time $400 \mathrm{~ms}$. The 16 bit grey-scale images were then first filtered using a $3^{3}$ Gaussian filter with a standard deviation of 1.5 voxels and segmented. The segmentation threshold (3932) was selected such that it was between the peaks of ice and air in the histogram. $A \pm 5 \%$ change in the threshold (which overestimates or underestimates the boundary very clearly) causes a $0.7 / 0.9 \%$ overestimate/underestimate of the porosity. So the precision of the micro-CT is better than $1 \%$, and for the SSA, it is around 2-3\% [Kerbrat et al., 2008].

[27] The densities of the surface samples processed by micro-CT ranged from 668 to $868 \mathrm{~kg} \mathrm{~m}^{-3}$ when measured using caliper and a scale, and from 736 to $894 \mathrm{~kg} \mathrm{~m}^{-3}$ when calculated from micro-CT results. The samples had been cut with a band saw, which does not produce a smooth surface, so the caliper measurement underestimates the density.
The samples cut out of the cores for measurement by microCT were small (diameter $36 \mathrm{~mm}$ ), and most of them do not include any cracks, so those measurements could underestimate the amount of bubbles and therefore overestimate the bulk density of the ice. The actual density is therefore probably intermediate between the two measurements. The SSA is linearly correlated with density above $\sim 600 \mathrm{~kg} \mathrm{~m}^{-3}$ (Figure 8); we will use this information below in our parameterization of broadband albedo.

[28] The near-surface ice in the Allan Hills (e.g., Figures 9c and 9d), which originates $\sim 25-40 \mathrm{~km}$ upstream and is exhumed from $\sim 500-1000 \mathrm{~m}$ depth [Nishio et al., 1982; Spaulding et al., 2012], has little in common with the ice at $10 \mathrm{~m}$ depth (e.g., Figure 9e), which has not yet been subject to surface temperature gradients. The surface ice has numerous cracks (e.g., Figures 5, 7, and 9c) and irregular nonspherical bubbles. We think that both characteristics are caused by the seasonal temperature cycles, which is probably $\sim 30 \mathrm{~K}$ as elsewhere on the East Antarctic Plateau [Warren and Town, 2011, Figure 2]. This is the difference between the average temperatures of the warmest and coldest months. The difference between warmest and

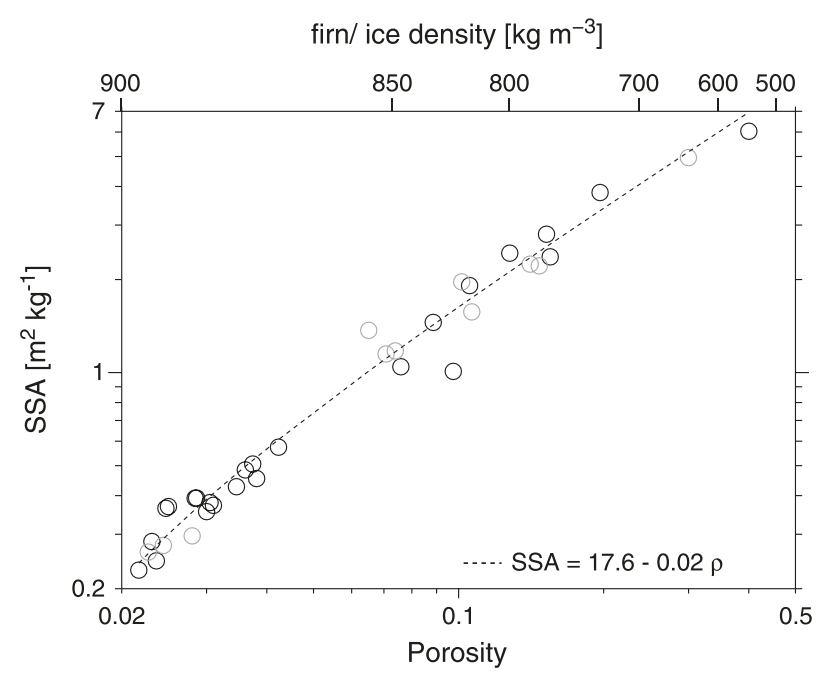

Figure 8. Specific surface area (SSA) from microcomputed tomography (micro-CT) versus porosity. Black circles are full samples, and gray circles are subsamples that were evaluated to analyze cracked and noncracked areas. The dashed line is the linear best fit between density and SSA for all samples with $\rho>650 \mathrm{~kg} \mathrm{~m}^{-3}$. 


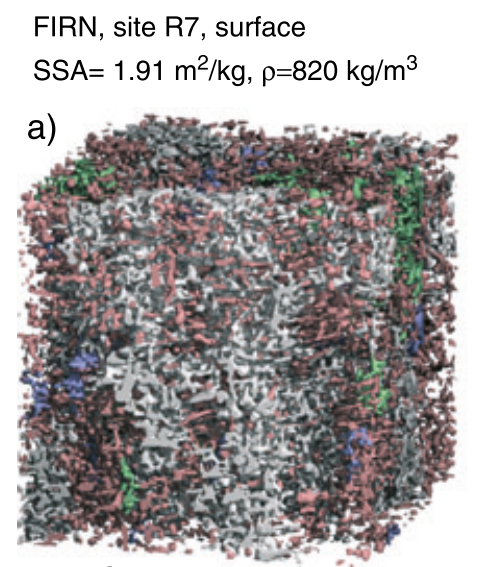

BLUE ICE, site R3, surface $\mathrm{SSA}=0.36 \mathrm{~m}^{2} / \mathrm{kg}, \rho=894 \mathrm{~kg} / \mathrm{m}^{3}$

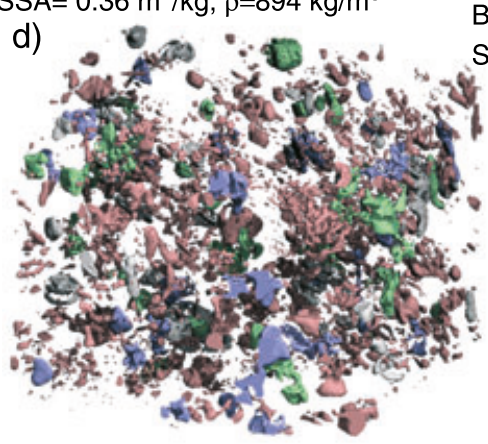

WHITE ICE, site R6, surface

$\mathrm{SSA}=1.04 \mathrm{~m}^{2} / \mathrm{kg}, \rho=847 \mathrm{~kg} / \mathrm{m}^{3}$
BLUE ICE, site R1, 0.3-0.32 m

$\mathrm{SSA}=0.57 \mathrm{~m}^{2} / \mathrm{kg}, \rho=878 \mathrm{~kg} / \mathrm{m}^{3}$

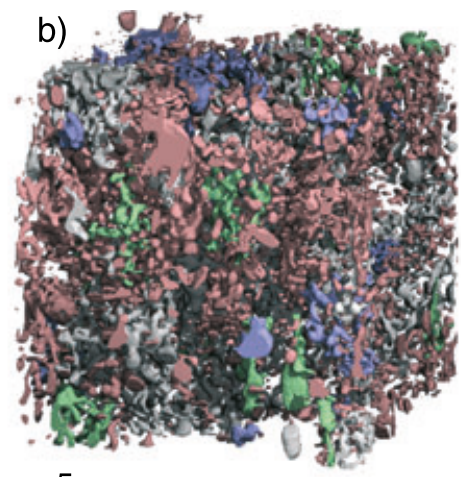

$5 \mathrm{~mm}$

BLUE ICE, site UM, $10.2 \mathrm{~m}$ $\mathrm{SSA}=0.17 \mathrm{~m}^{2} / \mathrm{kg}, \rho=894 \mathrm{~kg} / \mathrm{m}^{3}$

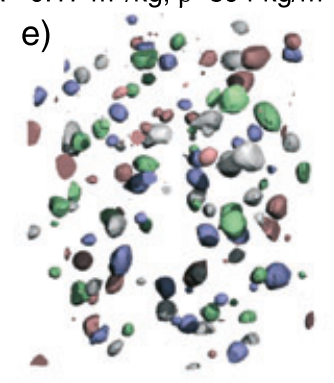

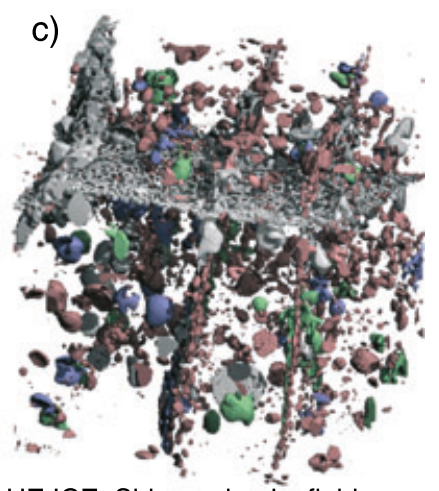

BLUE ICE, Shimmering İcefield, $\mathrm{SSA}=0.15 \mathrm{~m}^{2} / \mathrm{kg}, \rho=882 \mathrm{~kg} / \mathrm{m}^{3}$

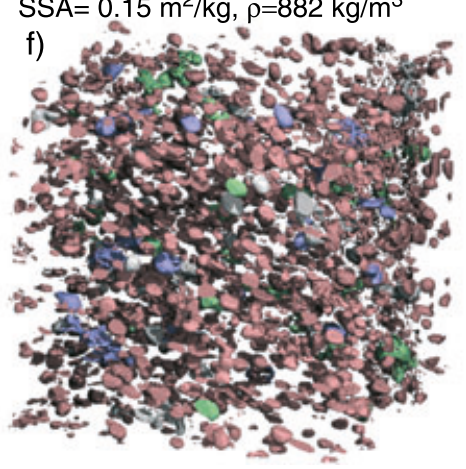

Figure 9. Examples of microcomputed tomography (micro-CT) models of sampled firn and ice in the Allan Hills. The colored regions are bubbles (air); ice is blank. Different colors indicate contiguous air spaces.

coldest days would be $\sim 60 \mathrm{~K}$ [Nishio et al., 1982]; the appropriate measure is probably intermediate between these values [Gold, 1963]. The surface ice contracts in winter and expands in summer. The cracks can form as deep as the annual temperature cycle penetrates, which is $\sim 4-5 \mathrm{~m}$. The cracks in the ice do not consist of just two planes with air in between, but become, during the healing of the crack, first a network of connected pores and later of bubbles within the crack plane (an example of bubbles along a plane is shown in Figure 9c). Depending on the age of the crack and how much time the ice has had time to sinter together, the cracks can consist either of continuous air spaces or of isolated bubbles that are aligned along an old crack plane. Either way, the cracks increase the amount of air spaces/bubbles in the sample and hence the SSA, which determines the ice albedo.

[29] Apart from causing cracks in the ice, the seasonal temperature cycle is probably also responsible for the complicated shapes of bubbles in the near-surface ice (Figures 9c, 9d, and 7). The temperature gradients in the top few meters of the ice cause the air bubbles to slowly migrate toward the warmer ice [Nakaya, 1956; Stehle, 1967; Shreve, 1967; Dadic et al., 2010]. The migration is caused by sublimation of ice at the warm end of a bubble and deposition of water vapor at the cold end. The migration rate depends on the ice temperature, the temperature gradient across the bubble, bubble pressure, and bubble shape [Shreve, 1967]. Experiments show that bubbles can change shape during migration [Dadic et al., 2010]. The seasonal cycles of surface temperature can cause near-surface bubbles to move alternately up and down, thus leading to complicated bubble shapes, as are observed near the ice surface in the Allan Hills. Considering the sublimation rate on the Main Ice Field (MIF) in the Allan Hills of 30-50 $\mathrm{mm} \mathrm{yr}^{-1}$ [Nishio and Annexstad, 1980; Faure and Buchanan, 1991; Spaulding et al., 2012] and ice velocities of $<0.2 \mathrm{~m} \mathrm{yr}^{-1}$ [Spaulding et al., 2012], ice remains in the zone of seasonal temperature variations (top $5 \mathrm{~m}$ ) for approximately 100-160 years (or 100-160 seasonal temperature cycles). The numerous cracks and complicated bubble shapes are therefore not surprising.

[30] Some of the cracking and nonsphericity of the bubbles could also be caused by the depressurizing of the ice as it comes to the surface from greater depth. We think that the effect of the depressurization is unimportant because (a) the ice at $10 \mathrm{~m}$ depth (i.e., an added pressure of just 1 bar), which has not been subject to processes related to temperature cycling, is crack-free with well-defined spherical air bubbles (Figure 9e), and (b) the surface ice from the Shimmering Icefield within the Allan Hills (Figure 3) largely consists of spherical air bubbles (Figure 9f). The terminus of the Shimmering Icefield, where our ice sample is from, lies in an area of higher summer air temperatures due to its proximity to land on three sides, and in fact, we found small pools of liquid water on the east margin. It therefore probably has higher sublimation rates, so the ice would spend less time in the zone of alternating temperature gradients, and the thermal-cycling effects would be smaller. 


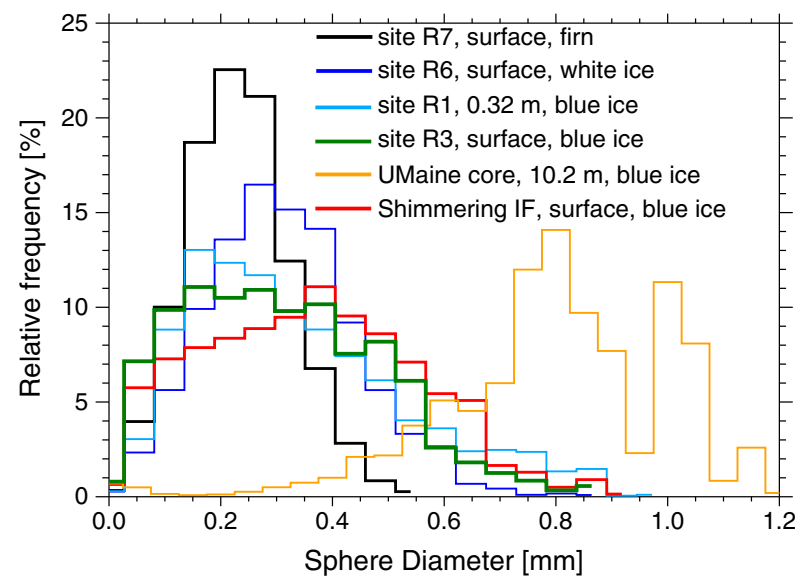

Figure 10. Size distribution of the "mean thickness" of pore spaces, as determined by evaluating the micro-CT images with the algorithm of Hildebrand and Rüegsegger [1997]. If the bubbles were perfect isolated spheres, each modeled sphere would represent exactly one bubble. Because the bubbles in our samples were not spheres, the size distribution rather represents the typical curvature of partial spheres. This technique is generally used and is like virtual sieving, so it gives the correct size distribution if we would have "sieved" the pore space.

[31] The SSA along the R-transect decreases from $3.82 \mathrm{~m}^{2} \mathrm{~kg}^{-1}$ in firn (at site R9) to $0.36 \mathrm{~m}^{2} \mathrm{~kg}^{-1}$ in blue ice at R3 (Figure 9). If we evaluate just the noncracked part of the ice at R1, the SSA is as low as $0.28 \mathrm{~m}^{2} \mathrm{~kg}^{-1}$. The SSA of ice at $10 \mathrm{~m}$ depth, which has not been subjected to seasonal temperature cycles, is $0.16 \mathrm{~m}^{2} \mathrm{~kg}^{-1}$. As firn densifies, the SSA decreases and the pore spaces become larger (Figure 9). We observe continuous pore spaces in our samples up to a density of $835 \mathrm{~kg} \mathrm{~m}^{-3}$ (measured by micro-CT), and the pore spaces are closed off for densities higher than $835 \mathrm{~kg} \mathrm{~m}^{-3}$ (Figure 9).

[32] The histogram of bubble size distribution cannot be uniquely defined if the bubbles are not spherical. Hildebrand and Rüegsegger [1997] developed an algorithm which is suitable for complex shapes, and we used it to evaluate the micro-CT images. In this algorithm, the air space is filled with the largest possible sphere and then fills the space around it with smaller spheres. If the bubbles were perfect isolated spheres, each modeled sphere would represent exactly one bubble. Because our samples do not consist of perfect bubbles, the size distribution rather represents the typical curvature of partial spheres. The technique is generally used and is like virtual sieving, so it gives the correct size distribution if we would have "sieved" the pore space. For firn, Figure 10 (black line) shows a narrow normal distribution, where small air spaces of width $0.2-0.3 \mathrm{~mm}$ are most frequent. As we go farther along the transect toward older ice that came through greater depths (toward R1), the size distribution widens. But for all surface samples, the most frequent width of air spaces remains at $0.2-0.3 \mathrm{~mm}$. The distribution is usually skewed toward larger spheres. The high frequency of small spheres in surface ice is caused by cracks and small irregular bubbles, both of which are caused by seasonal temperature cycles. Daily temperature cycles would have a similar effect but would affect only the top $200 \mathrm{~mm}$ of the ice. Assuming the same surface sublimation rate of $\sim 30-50 \mathrm{~mm} \mathrm{yr}^{-1}$, the ice would be exposed to daily temperature fluctuations for only 4-6 years and would therefore have fewer cracks and small, irregular bubbles. The sphere size distribution in the Shimmering Icefield surface ice is less skewed and peaks at $0.4 \mathrm{~mm}$ (Figure 10, red line). The ice from $10 \mathrm{~m}$ depth (from the Allan Hills Main Icefield) is skewed toward smaller spheres (Figure 10, orange line); the mode size is around $0.8 \mathrm{~mm}$.

\subsection{Crack Fraction}

[33] We use stereology to estimate crack planar area $\left(A_{p}\right)$ in a volume from random two-dimensional images of the surface (Figure 5). We used a design-based sampling scheme that makes no statistical assumption about the shape or distribution of the analyzed features [Baddeley et al., 1986; Riche et al., 2012]. Ten randomly placed and oriented pictures were taken at each site within a radius of about $5 \mathrm{~m}$. We used the STEPanizer stereology online tool [Tschanz et al., 2010] to evaluate the pictures. STEPanizer overlays cycloids on a regular grid over the original image of the ice surface. We then count how many times the cycloids intersect any cracks in each of the 10 images; we counted up to 250-400 intersection in ice (25-80 in firn), which is considered sufficient. From the number of intersections, we calculated the crack planar area $\left(A_{p}\right)$ per volume $\left(\mathrm{m}^{2} \mathrm{~m}^{-3}\right)$. Details on this technique and the equations can be found in Tschanz et al. [2010] or Matzl and Schneebeli [2010].

[34] The planar crack area for the evaluated Allan Hills sites increases with increasing density (Figure 11). It is up to 10 times higher for ice $\left(\rho>830 \mathrm{~kg} \mathrm{~m}^{-3}\right)$ than for firn. The reduced number of cracks in firn is caused by the much higher ductility of firn compared to ice. In addition, microcracks between firn structures will heal much faster than in ice, due to the lower viscosity of firn. Strain in firn is accommodated by microcracks between the sintered ice grains,

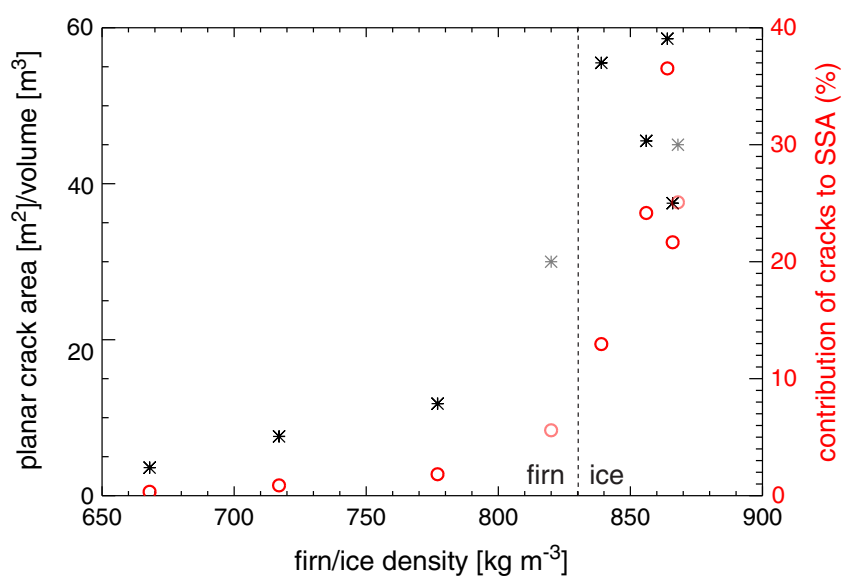

Figure 11. Crack planar area per volume (asterisks) and contribution of cracks to the SSA (circles), versus density. Gray and light red symbols represent two sites where we did not have any images to estimate the crack planar area $\left(A_{p}\right)$ using stereology, so we approximated $A_{p}$ from the measured density at these sites and the density- $A_{p}$ correlation we got from other sites. 
Table 2. Effect of Cracks on Broadband Albedo ${ }^{\mathrm{a}}$

\begin{tabular}{lccccccc}
\hline Site & Description & $\begin{array}{c}\text { SSA From Albedo } \\
\text { Model }\left(\mathrm{m}^{2} / \mathrm{kg}\right)\end{array}$ & $\begin{array}{c}\text { Fraction of SSA } \\
\text { Due to Cracks }(\%)\end{array}$ & $\begin{array}{c}\text { Cracks } \\
\text { Only }\end{array}$ & $\begin{array}{c}\text { Bubbles } \\
\text { Only }\end{array}$ & $\begin{array}{c}\text { Bubbles } \\
\text { +Cracks }\end{array}$ & $\begin{array}{c}\text { Change From Bubble-Only Albedo } \\
\text { to Bubbles-Plus-Cracks Albedo }\end{array}$ \\
\hline R1 & Blue ice & 0.65 & 37 & 0.495 & 0.547 & 0.574 & 0.027 \\
R6 & White ice & 1.4 & 13 & 0.492 & 0.616 & 0.626 & 0.009 \\
R7 & Firn & 3.87 & 2 & 0.413 & 0.689 & 0.690 & 0.001 \\
\hline
\end{tabular}

${ }^{\text {a }}$ Total solar albedo $(0.3-3.0 \mu \mathrm{m})$ for ALH clear-sky solar spectrum.

so crack propagation in firn is limited to the submillimeter scale. However, in ice, the strain cannot be accommodated easily, so cracks propagate and form a dense network. Interestingly, the air bubbles seemed not to be important for crack propagation, or only in rare cases. We further see a sharp transition in Figure 11 between firn and ice, both in the crack area and in the relative contribution of crack area to total SSA.

[35] The crack planar area does not tell us yet how much SSA is contained in the cracks, and we can not extract that information from the crack images, where a crack is only visible as a line (Figure 5). Instead, we use the micro-CT measurements and subsample cracks to estimate $r$, which is the bubble surface area $\left(A_{s}\right)$ in the cracks (area of air-ice interfaces) contained per planar crack area $\left(A_{p}\right)$ along which the bubbles are concentrated. The mean value of $r=\left(A_{s} / A_{p}\right)$ for 10 evaluated cracks was $2.35(r=2$ means that each crack consists of two flat sides). We can now multiply the $A_{p}$ estimated at each site (Figure 11) by $r$, and add this new additional bubble surface area to the bubble surface area of the sample without cracks to estimate a new SSA that accounts for bubbles in cracks. The highest contribution of cracks to SSA is $37 \%$ at site $\mathrm{R} 1$ and drops to $0.3 \%$ at the firnsite R9 (right-hand axis of Figure 11). The contribution of cracks to the SSA increases with increasing density, because $A_{p}$ increases with density and SSA decreases with density (Figure 11). The augmentation of SSA by cracks does not cause much increase in albedo (e.g., $\sim 0.03$ for blue ice), as shown in Table 2 and explained in section 7.2 below.

\section{Light Absorption by Volcanic Ash}

[36] The ice contains some impurities, mostly tephra (ash) from Antarctic volcanoes [Nishio et al., 1985]. The thin ash layers are visible at places in the ice. They were presumably originally horizontal but have been tilted by shearing deformation with ice sheet flow, so the layers are seen to dip at a variety of angles down from where they outcrop. For our radiation measurements, we avoided locations where ash was visible. However, there were surely small amounts of subvisible ash affecting all our measurements.

[37] Several of our $1 \mathrm{~m}$ ice cores contained significant amounts of ash. Five samples from three different cores were melted; the meltwater from each was then filtered through a $0.4 \mu \mathrm{m}$ nuclepore filter. The volumes ranged from 300 to $1200 \mathrm{~mL}$. The filters were analyzed by the same method we use to quantify light-absorbing impurities in snow [Doherty et al., 2010; Grenfell et al., 2011], calibrated against standard reference filters containing known amounts of black carbon with a mass absorption cross section (MAC) of $6 \mathrm{~m}^{2} / \mathrm{g}$ at wavelength $\lambda=550 \mathrm{~nm}$ and an absorption Ångström exponent of 1.0 [Grenfell et al., 2011]. This procedure gives the absorption optical depth on the filter as a function of wavelength, for $400-750 \mathrm{~nm}$. The filters were weighed both
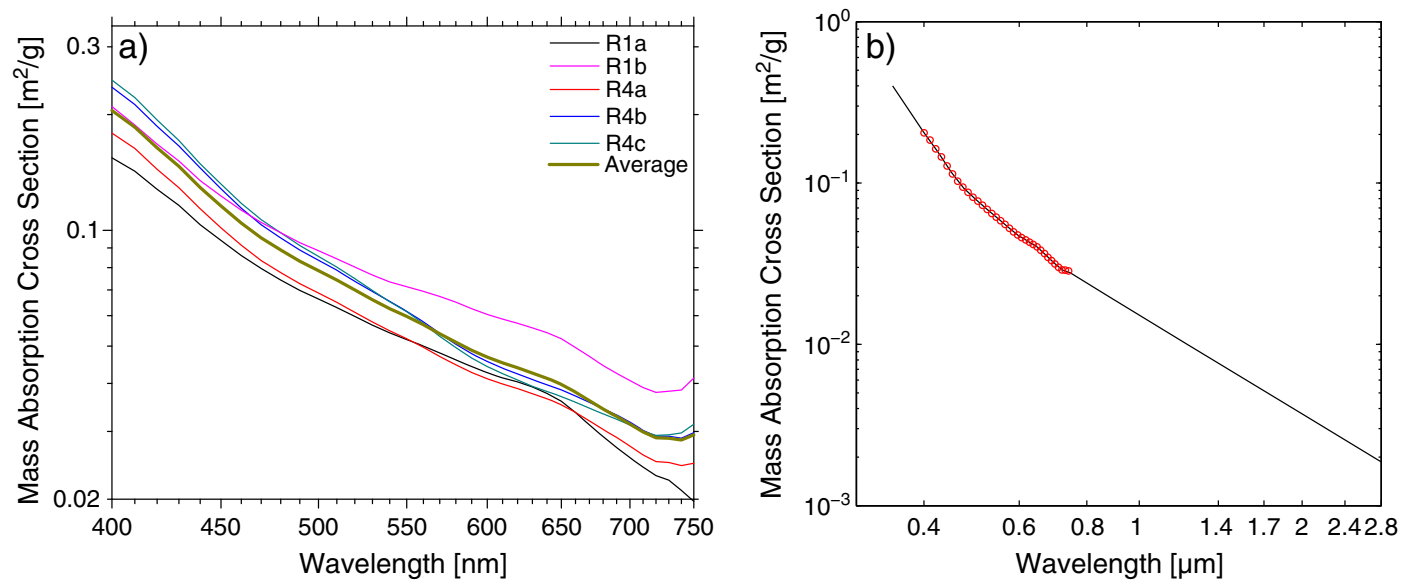

Figure 12. Absorption spectrum of volcanic ash. Five near-surface ice core samples were melted and filtered; the filters were weighed. The particulate absorption was measured on the integrating spheresandwich (ISSW) spectrophotometer [Grenfell et al., 2011]. (a) Mass absorption cross section (MAC) versus wavelength for the five samples, as well as the average of all five. (b) The average spectrum from Figure 12a (red circles) is extrapolated to shorter and longer wavelengths (blue line) for use in the radiative transfer modeling. The extrapolation assumes that $\log (\mathrm{MAC})$ is linear in $\log (\lambda)$. 
before and after filtration, on a Mettler MT5 electrobalance with a detection limit of $1 \mu \mathrm{g}$. The masses of ash on the filters ranged from 470 to $1100 \mu \mathrm{g}$; the mass fractions of ash in these ice samples ranged from 0.4 to $1.6 \mathrm{ppm}$.

[38] The exposed area of each filter was measured with a caliper; the filter loading (in $\mu \mathrm{g} \mathrm{m}^{-2}$ ) is determined by dividing the mass by the exposed area. The spectral MAC is then obtained by dividing the absorption optical depth by the loading. The resulting MAC for each of the five samples is shown in Figure 12a, along with the average of the five samples. At $\lambda=550 \mathrm{~nm}$, the derived MAC is a factor of 100 smaller than that of black carbon; a similar result was inferred for Mount St. Helens ash in Figure 7 and section H2 of Warren [1982].

[39] For the radiative transfer modeling, we need the ash absorption over the entire solar spectrum. The measured spectrum ("average" in Figure 12a) is extrapolated as shown in Figure $12 \mathrm{~b}$ to obtain the ash absorption spectrum for use in the modeling.

\section{Explaining the Spectral Albedo Measurements}

\subsection{Radiative Transfer Model}

[40] We use the "specular delta-Eddington" model that was developed by Mullen and Warren [1988, hereinafter MW] to model radiative transfer in lake ice including internal and external specular reflection at the upper ice surface. It incorporates a scattering layer, whose optical properties are computed using the delta-Eddington method [Joseph et al., 1976], capped by a flat interface that refracts and reflects incident radiation according to Fresnel's laws. The incident solar radiation is partly reflected by the specular surface and partly refracted into the bubbly ice below. The bubbles and cracks scatter light; upward-directed light reaching the top is partly reflected back downward by the specular surface, and there is a range of upgoing angles that experiences total internal reflection.

[41] The specular interface at the top of the multiplescattering medium occurs in ice but not in snow. In snow, the reflection and refraction at the topmost snow grain is not qualitatively different from the interactions of radiation with interior grains. The model was therefore made more general by allowing the specular interface to be gradually invoked for surfaces intermediate between snow and ice. A smoothness parameter $s$ indicates the degree of specularity: $s=1$ for a smooth flat ice surface and $s=0$ for a "rough" multiple-scattering medium lacking a specular surface, such as clouds or snow. For intermediate surfaces such as firn or white ice, $s$ is a tunable parameter with a value between 0 and 1 . This parameter multiplies each specular reflection coefficient and also gives a weighting to the angle of refraction. The equation for albedo $a$ (equation (5) of MW) then becomes

$$
a=s R_{1}+\frac{\left(1-s R_{1}\right) A\left(\mu_{e}\right)\left(1-s R_{2}\right)}{\left(1-s R_{2} A_{d}\right)},
$$

where $R_{1}$ is the external specular reflection coefficient (air to ice) and $R_{2}$ is the internal specular reflection coefficient (ice to air). For the multiple-scattering layer below the surface, $A\left(\mu_{e}\right)$ is the delta-Eddington albedo for a direct beam at the angle $\theta_{e}$ whose cosine is $\mu_{e}$, where

$$
\mu_{e}=s \mu_{t}+(1-s) \mu_{l},
$$

where $\mu_{l}$ is the cosine of the angle of incidence and $\mu_{t}$ is the cosine of the angle of the transmitted beam (the two angles are related by Snell's law). Finally, $A_{d}$ is the multiplescattering delta-Eddington albedo for the field of internally reflected radiation.

[42] The MW model required as input a size distribution of bubbles, or the effective radius of a size distribution together with a bubble number density. In this work, we have simplified the model, hypothesizing that to explain the albedo, the only information needed about the bubble size distribution is the specific surface area $\alpha$; i.e., the total surface area of all bubbles (and cracks) per unit mass of ice. This is plausible because the bubbles are large compared to the wavelengths of solar radiation, so the scattering efficiency is nearly independent of bubble size. Equation (3) gives the relation between $\alpha$ and the bubble size distribution $n(r)$ :

$$
\int 4 \pi r^{2} n(r) \mathrm{d} r=\alpha \rho
$$

where the units on the left-hand side are $\mathrm{m}^{2} \mathrm{~m}^{-3}$ (i.e., $\mathrm{m}^{2}$ of bubble surface area per $\mathrm{m}^{3}$ of volume); units of $\alpha$ are $\mathrm{m}^{2} / \mathrm{kg}$, and $\rho$ is the ice density $\left(\mathrm{kg} / \mathrm{m}^{3}\right)$. The reformulated model (written to take SSA as input) was run for several of the cases that had been plotted by MW, and the results were identical.

[43] The multiple-scattering computation using deltaEddington requires, at each wavelength, values of absorption coefficient, scattering coefficient, and asymmetry parameter $g$. The asymmetry parameter is the average cosine of the scattering angle, $-1 \leq g \leq 1$, and for spherical scatterers is generally in the range $0.85-0.9$ for the sizes of snow grains and air bubbles in the surfaces we measured. We use the parameterization for $g$ shown in Figure 1 of MW; unlike the case for ice spheres, $g$ for air bubbles is nearly independent of $r$ because air bubbles are nonabsorbing. Below, we discuss the errors caused by using this parameterization for bubbles of nonspherical shapes. The scattering coefficient, with units $\mathrm{m}^{-1}$, is

$$
k_{\text {sca }}=Q_{\text {sca }} \alpha \rho / 4,
$$

where $Q_{\text {sca }}$ is the scattering efficiency, which we set equal to 2.0 independent of wavelength as in MW, as appropriate for bubble radius $r \gg \lambda$, so

$$
k_{\mathrm{sca}}=\alpha \rho / 2 .
$$

The absorption coefficient, also with units $\mathrm{m}^{-1}$, is

$$
k_{\mathrm{abs}}=\frac{\rho}{\rho_{\mathrm{ice}}} k_{\mathrm{abs}}^{\mathrm{ice}}+\beta c \rho,
$$

where $k_{\mathrm{abs}}^{\text {ice }}$ is the spectral absorption coefficient of pure ice [Warren and Brandt, 2008], $\beta$ is the spectral MAC of the ash $\left(\mathrm{m}^{2} / \mathrm{kg}\right)$, and $c$ is the mass-mixing ratio of ash in ice.

\subsection{Matching the Measured Albedos}

[44] The model has three variables that can be adjusted to match a measured albedo spectrum: the specific surface area $\alpha$, the smoothness parameter $s$, and the ash mixing ratio $c$. (Below in section 6.3, we examine the consequences of adjusting the asymmetry factor instead of the SSA.) Of these three, the most important variable is $\alpha$, which affects the entire spectrum. The effects of $c$ are significant only in the visible and near-UV, $\lambda \leq 0.6 \mu \mathrm{m}$. For most of the spectrum, the specular reflection actually reduces the albedo, 


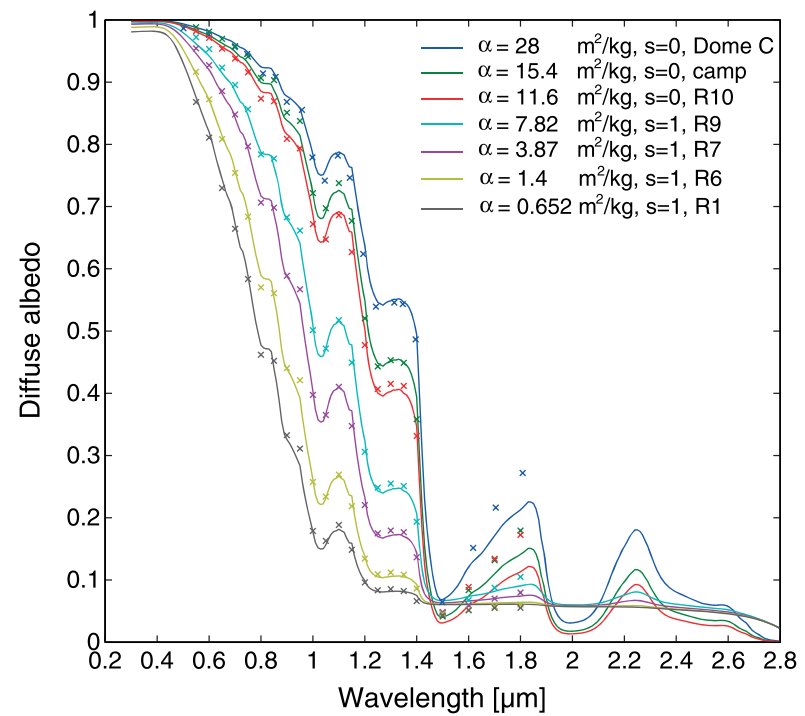

Figure 13. Model calculations of spectral albedo for seven surfaces, adjusting SSA to best fit the measurements at these sites at wavelengths indicated by " $\times$." Wavelengths affected by volcanic ash $(0.3-0.5 \mu \mathrm{m})$ are not used in the fitting for this figure.

because its reflection of upward radiation back down into the ice (including total internal reflection) exceeds its mirror reflection of the incoming solar beam, as explained by MW. Only around 1.5 and $2.0 \mu \mathrm{m}$ is the multiple-scattering albedo so low that the albedo is dominated by the specular reflection, so that only at those wavelengths can the albedo of ice exceed that of snow (MW, Figure 12).

[45] We tried a global error-minimization routine to adjust both $\alpha$ and $s$ to get the best fit, but that procedure resulted in unreasonable values of $s$ (e.g., $s=0.8$ for snow, instead of $s=0$ ) because of a process not accounted for in our modeling, namely the decrease of SSA with depth. Snow grain size increases with age by "destructive metamorphism" [LaChapelle, 1969], which results in an increase of grain size with depth (and a corresponding decrease of SSA), as is commonly seen, and this systematic increase was invoked by Grenfell et al. [1994] to explain spectral albedos of Antarctic snow. In ice, the SSA is likewise larger at the top, for

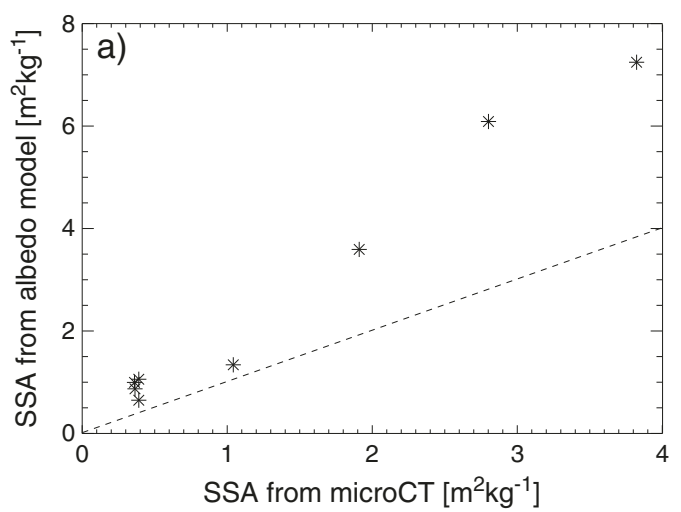

reasons explained above having to do with larger temperature gradients. The MW model uses only a single value of $\alpha$ to describe the full depth of the snowpack or ice sheet, so the minimization procedure was inappropriately adjusting $s$ to better match albedos in the $1.4-1.8 \mu \mathrm{m}$ region. For the results we present here, we have just specified $s=0$ for snow and $s=1$ for firn and ice.

[46] Figure 13 shows the spectral albedos measured at five sites on our transect near the Allan Hills, as well as that of snow higher on the plateau at Dome C [Hudson et al., 2006, Figure 6]. The solid curves are the model calculations, fitted to the experimental points indicated by " $\times$." Only $\alpha$ was adjusted for this fit, so the data for $\lambda<0.5 \mu \mathrm{m}$ are omitted from this plot because absorption by ash becomes significant there. The data become noisy beyond $1.8 \mu \mathrm{m}$, so the fitting of the model to measurements by adjusting $\alpha$ uses only the measurements for $0.5-1.8 \mu \mathrm{m}$.

[47] The biggest discrepancy between model and measurement is at 1.6-1.8 $\mu \mathrm{m}$; a two-layer model with SSA decreasing with depth would provide a better match. A larger SSA at the surface than at depth is usual for Antarctic snow because of destructive metamorphism and because of grain sorting with wind-drifting [Grenfell et al., 1994, p. 18674]. A larger surface SSA also occurs in blue ice as release of pressure causes bubbles to grow and temperature gradients cause cracks to form. The different wavelengths are influenced by SSA at different depths. At 1.6-1.8 $\mu \mathrm{m}$, ice is more absorptive than at shorter wavelengths so the light does not penetrate as deeply and is sensitive to the SSA only of the topmost layers. Finding the SSA that matches albedo at $\lambda<1.4 \mu \mathrm{m}$ and then using this SSA at all wavelengths will therefore predict albedos too low at 1.6-1.8 $\mu \mathrm{m}$. This is shown in Figure 4 of Grenfell et al. [1994], and more clearly in Figure 1 of Warren et al. [1986].

\subsection{Specific Surface Area From Microcomputed Tomography Versus Specific Surface Area From Spectral Albedo}

[48] The measured SSA determined from micro-CT is, for most of the ice types, $\sim 50 \%$ lower than the modeled SSA needed to explain the spectral albedo (Figure 14). There are several possible explanations for the discrepancy, either that the SSA from micro-CT was erroneously low (items 1-5

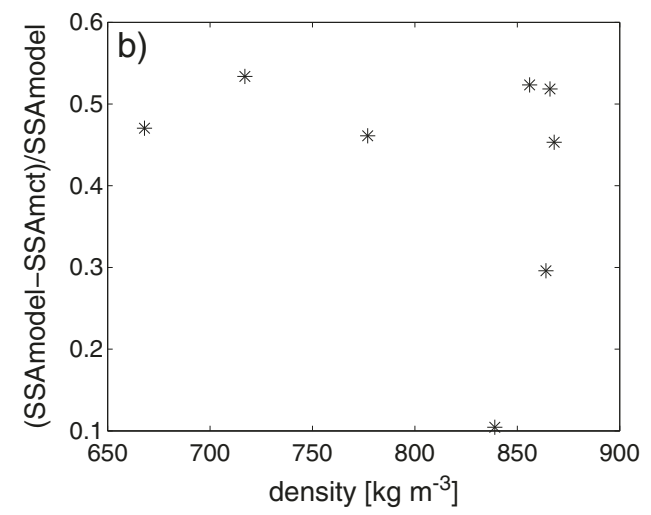

Figure 14. (a) Comparison of SSA from micro-CT measurements with SSA inferred from spectral albedo measurements. The dashed line is the 1:1 line. (b) Fractional difference of the two estimates, as a function of density. 


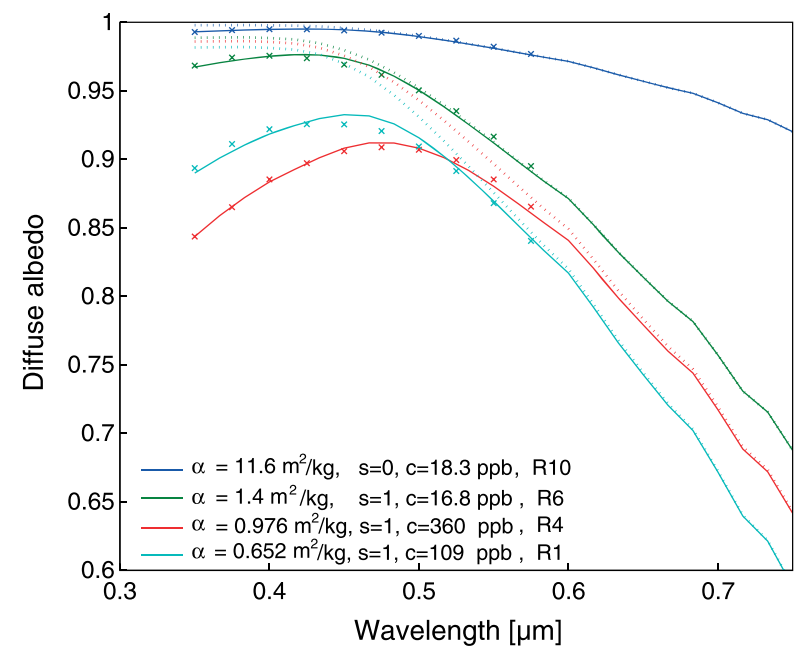

Figure 15. Albedo for diffuse illumination (measured under overcast cloud) in the visible and near-UV region, showing the influence of absorption by volcanic ash. Dashed curves are the albedo of pure snow, firn, or ice whose SSA was determined by fitting the spectral albedo for $\lambda>0.6 \mu \mathrm{m}$. The solid curves are albedo for the same SSA but with added ash whose absorption spectrum is given in Figure 12. The concentrations needed to match the observed albedos (points labeled " $x$ ") range from 17 to $360 \mathrm{ppb}$, as given in the legend.

below) or that the SSA from the albedo model was erroneously high (item 6). We think that explanation 6 is the most plausible.

[49] 1. Most samples for micro-CT did not include cracks, due to limited sample size. Addition of cracks would increase the SSA, but only for the ice samples $\left(\rho>830 \mathrm{~kg} \mathrm{~m}^{-3}\right)$, not the firn samples on the left side of Figures 11 and 14b. Table 1 shows the limited increase in SSA due to cracks, with a minimum SSA increase for firn $(+0.3 \%)$ and a maximum increase for ice with highest density $(+32 \%)$.

[50] 2. There could be subgrid-scale roughness on the bubbles that was not resolved by the micro-CT with voxel size $18 \mu \mathrm{m}$. Kerbrat et al. [2008] show that this is unlikely, as their comparison of SSA from micro-CT (30 $\mu \mathrm{m}$ resolution) and methane adsorption yields identical results, except for very fresh snow. They thus conclude that "aged natural snow is smooth up to a scale of about $30 \mu \mathrm{m}$ and that if smaller structures are present, they do not contribute significantly to the overall SSA." At a temperature of $-25^{\circ} \mathrm{C}$ (typical measured summer ice temperature in the Allan Hills), the radius of the smallest structure is larger than $20 \mu \mathrm{m}$ within about 5 days. So the micro-CT measurements are able to measure all ice structures except the very few cracks younger than 5 days. Furthermore, Figure 10 shows that the peak of the size distribution of the bubbles is about a factor of 10 larger than the resolution of the micro-CT. So the fraction of bubbles below the resolution is below about $2 \%$. In addition, there is no hint in the size distribution that there is a hidden bimodal distribution (with much smaller bubbles), as that would show up with a high value in the lowest bin.
[51] 3. The SSA may be larger in the top centimeter (which is most important for determining albedo) than in the small cylinder extracted from the core for the microCT analysis (which was some small distance below the top surface). A two-layer model could possibly account for the decrease in SSA with depth, but this is beyond the scope of this project.

[52] 4. There is always a small amount of snow dust on the surface. The SSA of new snow is larger than $60 \mathrm{~m}^{2} \mathrm{~kg}^{-1}$, and even small rounded grains have $\sim 30 \mathrm{~m}^{2} \mathrm{~kg}^{-1}$. So even a tiny amount of snow dust has huge effect on the albedo at wavelengths where the albedo is low, as mentioned above. A few percent of snow dust on the surface may have a significant effect on the SSA.

[53] 5. The SSA may have decreased during the time that the cores were in storage before being analyzed in the laboratory. The cores were stored for several weeks, during which time they were not experiencing temperature gradients due to diurnal cycles and weather events, so destructive metamorphism would be expected to cause a decrease in the SSA of the firn cores. Based on snow measurements, Kaempfer and Schneebeli [2007] show that the decrease in SSA is $\sim 40 \%$ at a constant temperature of $-19{ }^{\circ} \mathrm{C}$ over the period of 75 days (the maximum storage time for any our samples). Also, we do not see high-curvature frosting in bubbles even in the 2 weeks old samples where macroscopic thicksection images are available (Figure 7), so this explanation is unlikely.

[54] 6. The modeling used a wavelength-dependent asymmetry parameter $g$ that is appropriate for spherical bubbles (MW, Figure 1). Nonspherical particles usually scatter light less to the forward direction (where $g \approx 1$ ) and more to the side, lowering $g$ [e.g., Neshyba et al., 2003, Figure 7; Grenfell et al., 2005, Figure 4]. If in the modeling, we fix $\alpha$ as the value of SSA obtained from micro-CT, we can then match the albedo curves by adjusting $g$ instead of $\alpha$. Matching the curves in Figure 13 using the SSA measured by micro-CT then requires multiplying $g$ by factors ranging from 0.78 to 0.94 . It is actually $(1-g)$ that appears in the equations of the delta-Eddington radiative transfer model, and the albedo curves can be matched by multiplying $(1-g)$ by factors ranging from 1.3 to 2.3 . The same factor is used across the entire spectrum. The matches are good; multiplying $g$ by a constant factor works just as well as multiplying $(1-g)$. For scattering of light by hexagonal prisms of ice (as opposed to spheres), the ratio $(1-g)_{\text {prism }} /(1-g)_{\text {sphere }}$ can be as large as 2.2 , so this explanation is plausible.

\subsection{Albedo Reduction by Volcanic Ash}

[55] We went to the Allan Hills with the hope of finding nearly pure ice, but our measured albedos do show the influence of tephra from past eruptions of Antarctic volcanoes. With the model, we can compute spectral and broadband albedo both with and without tephra. Both cases may be relevant to Snowball Earth; the model for pure bubbly ice early in a snowball event, and ash-laden ice after millions of years of episodic ash-fall from volcanoes. In section 7 below, we will compute the broadband albedo as a function of ash content; in this section, we just attempt to explain the measured albedos.

[56] Figure 15 shows that matching the observed albedos in wavelengths $0.35-0.5 \mu \mathrm{m}$, using the MAC of ash from 


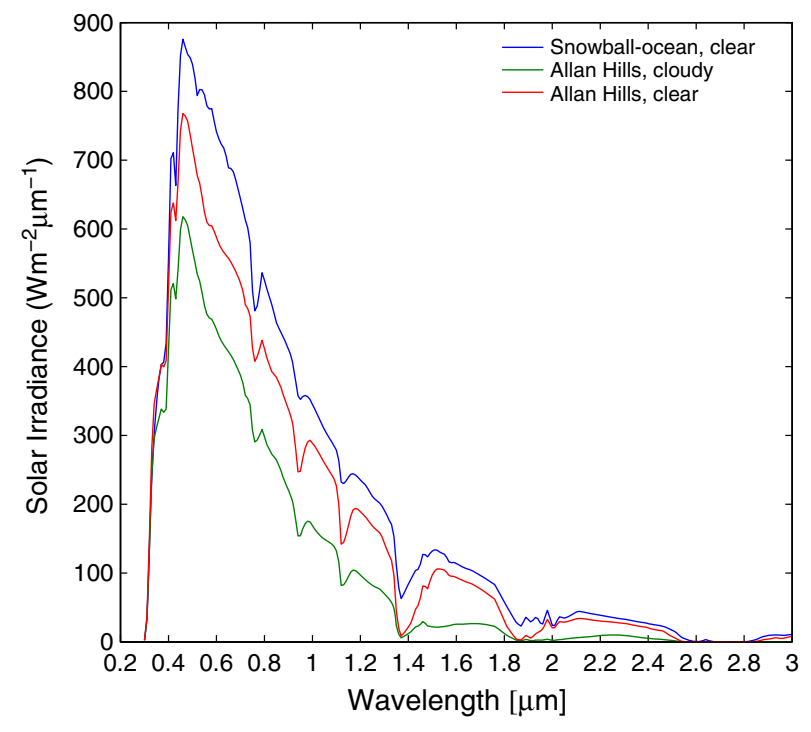

Figure 16. Solar radiation spectrum incident on the ice surface, for three atmospheric conditions: clear sky in the Allan Hills (surface elevation $2000 \mathrm{~m}$ ), cloudy sky in the Allan Hills, and clear sky at sea level at the equator with atmospheric temperatures and water vapor corresponding to the coldest time during a snowball event.

Figure $12 \mathrm{~b}$, requires ash in amounts $17-360 \mathrm{ppb}$. This is 3-5 times less than the weighed ash content in the cores that were melted and filtered to obtain the ash absorption spectrum in Figure 12; this is to be expected because the core sections used were chosen for their high ash content (usually deeper within the core, not at the top), and albedo sites were selected where ash was not visibly apparent. The good match of the spectral shapes of the measured and modeled albedos indicates that it is indeed the volcanic ash that is causing the observed dropoff of albedo to the shorter wavelengths.

\section{Parameterization of Broadband Albedo}

[57] The aim of this section is to make the results of the fieldwork useful for climate models of Snowball Earth that

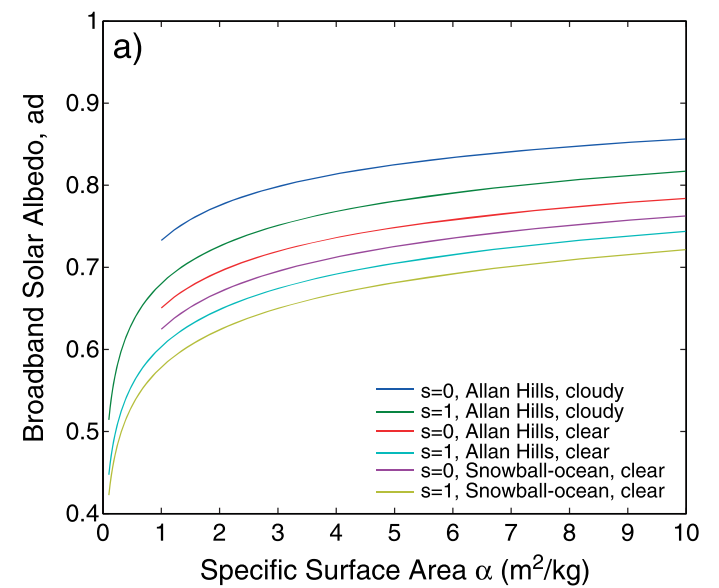

compute solar radiation using only one or two broad bands. The broadband albedo $\bar{a}$ is a weighted average of the spectral albedo, weighted by the incident solar spectral flux $F(\lambda)$ :

$$
\bar{a}=\frac{\int a(\lambda) F(\lambda) \mathrm{d} \lambda}{\int F(\lambda) \mathrm{d} \lambda},
$$

where $F(\lambda)$ has units $\mathrm{W} \mathrm{m}^{-2} \mu \mathrm{m}^{-1}$. The limits of integration for the total solar albedo are 0.3 and $3.0 \mu \mathrm{m}$. Many GCMs divide the solar spectrum into two parts, $\lambda<0.7 \mu \mathrm{m}$ and $\lambda>0.7 \mu \mathrm{m}$; for those GCMs, we need to provide $\bar{a}$ for each of the two spectral bands.

\subsection{Solar Spectra}

[58] The solar spectra we use are similar to two spectra we have used previously for clear and cloudy skies over the Antarctic Plateau [Brandt and Warren, 1993] and a third spectrum for a cold atmosphere with surface at sea level, to represent the ocean of Snowball Earth [Warren et al., 2002]. They are computed using the atmospheric radiation model 'ATRAD', which is described by Wiscombe et al. [1984]. The spectra are plotted in Figure 16. [The relative magnitudes of the three curves will vary with solar zenith angle and cloud thickness, but for equation (7), it is only their spectral shapes that matter, because $F(\lambda)$ is just a weighting function that enters both numerator and denominator.] The Allan Hills spectra are for surface elevation $2000 \mathrm{~m}$, surface temperature $-20^{\circ} \mathrm{C}$, tropospheric temperatures for January at the South Pole, and troposphere saturated with water vapor. The cloudy sky has in addition an overcast cloud of optical depth 5.6 with base at $1.4 \mathrm{~km}$ above the surface (cloud thickness of $1.6 \mathrm{~km}$ ). The snowball-ocean spectrum is the same as that shown in Figure 2 of Warren et al. [2002], but plotted here as a function of $\lambda$ rather than $\log \lambda$.

\subsection{Broadband Albedo as a Function of Specific Surface Area}

[59] Figure17 shows the modeled broadband albedo for pure bubbly ice as a function of SSA. The plot of $\bar{a}$ is concave downward in Figure $17 \mathrm{a}$; it rises rapidly for small $\alpha$ and then approaches an asymptote. This figure explains why either bubbles alone or cracks alone can give a high

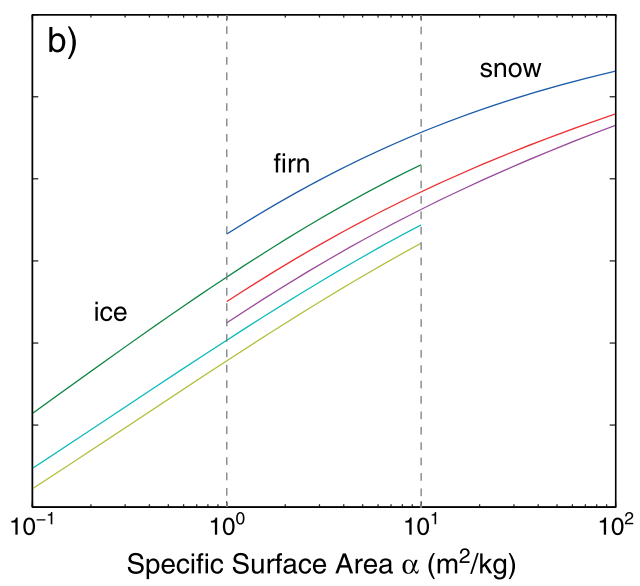

Figure 17. Broadband albedo for the total solar spectrum, 0.3-3.0 $\mu \mathrm{m}$, as a function of SSA, for the three solar spectra of Figure16, with specular reflection present $(s=1$, ice) or absent $(s=0$, snow). (a) SSA on linear scale. (b) SSA on logarithmic scale. 


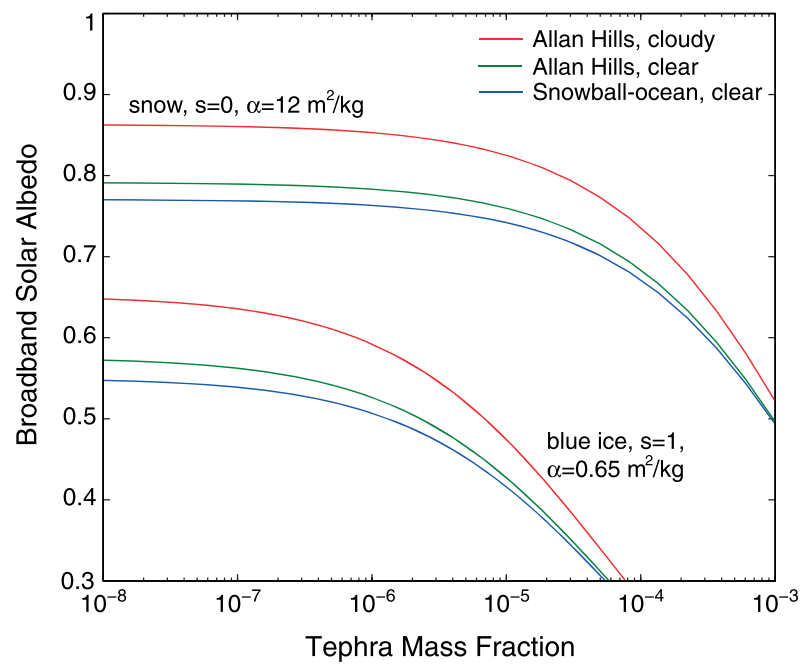

Figure 18. Broadband albedo as a function of mass fraction of volcanic ash, for two different SSAs characteristic of snow and blue ice, and for three incident spectra.

albedo, but adding cracks to bubbly ice does not increase the albedo by much. For example, Figure 17a shows that for $\alpha=3 \mathrm{~m}^{2} / \mathrm{kg}$ the albedo is 0.68 ; doubling the SSA to $\alpha=6 \mathrm{~m}^{2} / \mathrm{kg}$ causes the albedo to rise only by 0.04 , to 0.72 (light blue curve). For denser ice with a smaller SSA of $0.5 \mathrm{~m}^{2} / \mathrm{kg}$, doubling the SSA causes the albedo to increase from 0.55 to 0.60 . Examples from three of our albedo sites are shown in Table 2.

[60] Figure $17 \mathrm{~b}$ plots $\bar{a}$ versus SSA on a logarithmic scale, so as to cover the full range of SSA from snow to firn to ice. For this figure, we show results for specular reflection both included $(s=1$, ice $)$ and excluded $(s=0$, snow $)$; they overlap in the firn domain.

\subsection{Reduction of Broadband Albedo by Volcanic Ash}

[61] Figure 18 shows the reduction of broadband albedo by volcanic ash, for the three solar spectra and for two values of SSA, corresponding to snow and blue ice. In ice, an albedo reduction of 0.01 is reached at a mass fraction $c=10 \mathrm{ppb}$, but in snow not until $c \approx 1000 \mathrm{ppb}$.

\subsection{Parameterization of Albedo as a Function of Density}

[62] Although what determines the albedo is the SSA of bubbles or snow grains, it turns out that the broadband albedo also shows a systematic relation to the snow or ice density, suggesting that density might serve as a surrogate variable that will be easier to predict than SSA in any ice sheet model, using a parameterization for firn densification [e.g., Herron and Langway, 1980; Arnaud et al., 1998, 2000; Spencer et al., 2001; Salamatin et al., 2009]. By transforming the density into porosity, a plot of albedo versus the logarithm of porosity (Figure 19) results in a nearly straight line, which may provide a simple parameterization for modeling.

[63] For this plot, we want the albedos for ice that is uncontaminated by tephra. We therefore have used the SSA determined by the best fit of modeled spectral albedo to
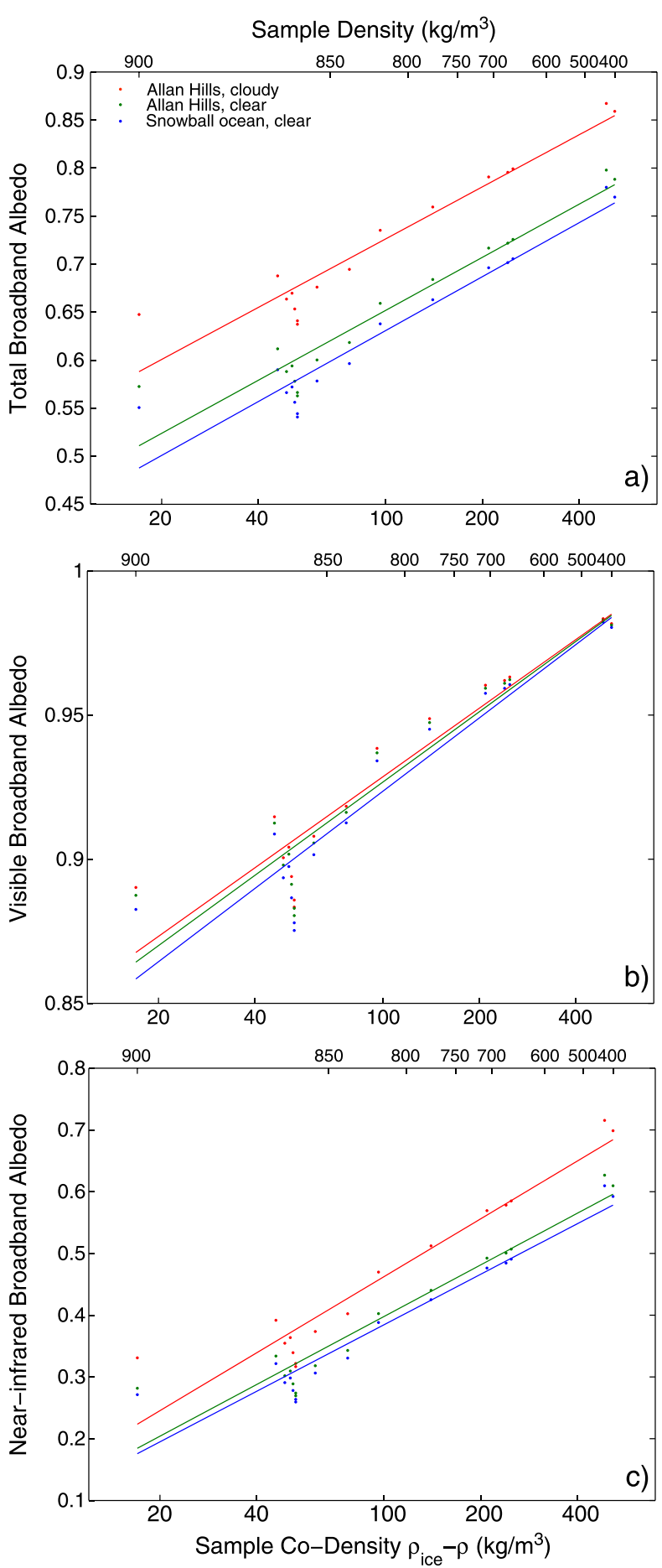

Figure 19. Broadband albedos computed from spectral albedos (some of which were shown in Figure 13), integrated over wavelength, weighted by the incident solar spectra of Figure 16. The surface types are here characterized by their densities $\rho$, and plotted versus $\left(\rho_{\text {ice }}-\rho\right)$, where $\rho_{\text {ice }}$ is the density of pure ice, $917 \mathrm{~kg} \mathrm{~m}^{-3}$. The corresponding density scale is shown along the top axis. These albedos are for pure snow or ice that contains no volcanic ash. (a) Total albedo, 0.3-3.0 $\mu \mathrm{m}$. (b) Visible and near-UV albedo, 0.3-0.7 $\mu \mathrm{m}$. (c) Near-infrared albedo, 0.7-3.0 $\mu \mathrm{m}$. The coefficients for the linear fits (equation (8)) are given in Table 3. 
Table 3. Coefficients for the Broadband Albedo Parameterization as a Function of Density (Equation (8)), Based on the Linear Fits in Figure 19

\begin{tabular}{lcccccc}
\hline & \multicolumn{5}{c}{ Spectral Band } \\
\cline { 2 - 7 } & UV-Visible & \multicolumn{2}{c}{ Near-Infrared } & \multicolumn{2}{c}{ Total Solar } \\
Atmosphere & $(0.3-0.7 \mu \mathrm{m})$ & \multicolumn{2}{c}{$(0.7-3.0 \mu \mathrm{m})$} & $(0.3-3.0 \mu \mathrm{m})$ \\
& $c_{1}$ & $c_{2}$ & $c_{1}$ & $c_{2}$ & $c_{1}$ & $c_{2}$ \\
\hline Allan Hills, cloudy & 0.034 & 0.77 & 0.135 & -0.16 & 0.078 & 0.37 \\
Allan Hills, clear & 0.035 & 0.76 & 0.120 & -0.16 & 0.080 & 0.29 \\
Snowball tropical & & & & & & \\
ocean, clear & 0.037 & 0.75 & 0.118 & -0.16 & 0.081 & 0.26 \\
\hline
\end{tabular}

measured spectral albedo in the region $0.6-1.8 \mu \mathrm{m}$, then computed the model albedo for that SSA for the entire spectrum, finally averaging the spectrum over wavelength (equation (7)) to get the broadband albedo.

[64] The following equation can describe the linear fits in Figure 19:

$$
\bar{a}=c_{1} \ln \left(\rho_{\text {ice }}-\rho\right)+c_{2},
$$

where $\bar{a}$ is the albedo, $\rho$ is the density of the ice or snow sample, and $\rho_{\text {ice }}$ is the density of pure ice, $917 \mathrm{~kg} \mathrm{~m}^{-3}$. The parameterization is valid for the density range of samples shown in Figure $19\left(400-900 \mathrm{~kg} \mathrm{~m}^{-3}\right)$. Table 3 gives the coefficients $c_{1}$ and $c_{2}$ for the linear fits, for each of the three atmospheric conditions, and for three spectral bands commonly used by GCMs.

\section{Relevance to Snowball Earth}

[65] There is strong geological evidence that, during the Neoproterozoic, glaciers extended to sea level at low latitude [Harland, 1964; Evans, 2000], but there is disagreement about the nature of the tropical ocean. Climate models that reduce greenhouse gases sufficiently to obtain sea-level glaciation at the equator obtain either a tropical ocean of open water [Chandler and Sohl, 2000; Hyde et al., 2000; Poulsen and Jacob, 2004; Micheels and Montenari, 2008], or thin ice [Pollard and Kasting, 2005], or thick ice [Goodman, 2006; Li and Pierrehumbert, 2011], depending on the type of model and the parameterizations used, particularly the albedo parameterizations.

[66] The surface albedo is important in several ways on Snowball Earth: Besides determining the ice thickness [Warren et al., 2002], which constrains potential refugia for photosynthetic life, it also determines (a) the drawdown of atmospheric $\mathrm{CO}_{2}$ necessary to initiate the snowball catastrophe, (b) the critical latitude for the ice albedo instability, (c) the surface temperatures, and (d) the duration of a snowball event (how much volcanic emission of $\mathrm{CO}_{2}$ is needed to warm the climate to melt the ice).

[67] Our focus in this paper is on oceanic processes during the coldest part of a "hard snowball" event, the first 0.1-1 Myr; this would be the most difficult time for survival of eukaryotic surface life, with ice likely hundreds of meters thick at all latitudes and always below freezing at the upper surface. On the hard snowball, daytime temperatures at the equator would likely have been no higher than $-30^{\circ} \mathrm{C}$ [Pollard and Kasting, 2004; Pierrehumbert, 2005]. "Sea glaciers" (flowing like modern ice shelves in response to their thickness gradient, but not dependent on continental glaciation) are computed to flow as much as $7-50 \mathrm{~m} / \mathrm{yr}$ even when they cover the entire ocean [Goodman, 2006; Li and Pierrehumbert, 2011].

[68] On the modern Earth, evaporation (E) exceeds precipitation (P) over nearly half the ocean, mostly in the tropics. A large region of negative P-E would also have existed on the Snowball Earth, according to general circulation models (GCMs), although the hydrological cycle was probably weakened by a factor of 30 [Pollard and Kasting, 2004]. The expected width of the negative P-E zone varies from $10^{\circ} \mathrm{N}-10^{\circ} \mathrm{S}$ [Pierrehumbert, 2005] to $30^{\circ} \mathrm{N}-30^{\circ} \mathrm{S}$ [Pollard and Kasting, 2004]. At low latitudes in the regions of net sublimation, the ocean surfaces would at first consist of bare sea ice with salt inclusions and would then probably develop a lag deposit of salt over the ice [Light et al., 2009]. After several thousand years, the sea ice would probably be crushed by the inflow of sea glaciers, several hundred meters thick, from higher latitudes [Goodman and Pierrehumbert, 2003]. The flow of a sea glacier would be driven by its thickness gradient, determined partly by the latitudinal gradient of surface temperature and partly by precipitation and sublimation rates [Goodman, 2006]. Pollard and Kasting [2005] argued that a narrow equatorial belt of thin sea ice could survive the invasion of the sea glaciers but that conclusion has been debated [Warren and Brandt, 2006; Pollard and Kasting, 2006].

[69] As sea glaciers flowed equatorward into the tropical region of net sublimation, their surface snow and subsurface firn would sublimate away, exposing bare glacier ice to the atmosphere and to solar radiation (Figure 1). This ice would be freshwater (meteoric) ice, which originated from compression of snow.

[70] Because of the long duration of a snowball event, we must consider whether the ice surface of a sublimating sea glacier will retain its high albedo as it ages, or whether it will become clearer. Bubbles in ice migrate slowly toward the warm end of a temperature gradient, because of vapor transport from the warm end to the cold end, potentially resulting in a lower surface albedo. This process was examined in cold-room laboratory experiments by Dadic et al. [2010]. From the experimental results, together with heatflow modeling, the migration rate at a glacier-ice surface can be computed as a function of surface temperature and ice thickness. It appears that the expected sublimation rate on the Snowball equator should exceed the bubble migration rate at all surface temperatures for all glacier-ice thicknesses $>0.3 \mathrm{~m}$, which means that the ice will retain its initial albedo. Dadic et al. [2010] therefore concluded that field measurements of albedo and bubble density on modern cold glacier ice will be of direct relevance to the surface of sea glaciers.

[71] The albedos that we measured are in the range previously reported for Antarctic blue ice areas, but they now are able to show the systematic transition for all intermediate states as a sea glacier flows from the midlatitudes into the tropics, if the Allan Hills ice can indeed represent sea glaciers. But there are several differences we must consider in establishing the relevance of our field measurements to Snowball Earth.

\subsection{Differences Between Antarctic Blue Ice and Subtropical Sea Glaciers}

[72] 1. Sea glaciers would have formed from snow that was colder and finer-grained than the snow of the East 
Antarctic Plateau. Lipenkov [2000] and Spencer et al. [2006] showed that ice-age ice contains many small bubbles, compared to Holocene ice with larger but fewer bubbles.

[73] 2. The sea glacier surface would be near sea level, and therefore at higher atmospheric pressure than the East Antarctic Plateau. The total air content could therefore be larger, perhaps by $20 \%$ [Martinerie et al., 1994, Figure 3a]. A related source of uncertainty is whether the Neoproterozoic sea-level pressure was similar to today.

[74] 3. The accumulation rate of snow on the midlatitude and polar oceans of a hard snowball would have been $<1 \mathrm{~mm} / \mathrm{yr}$ of liquid equivalent [Pollard and Kasting, 2004, Figure 9; Pierrehumbert, 2005, Figure 10], much smaller than in interior East Antarctica today. Lipenkov [2000] and Spencer et al. [2006] showed that a lower accumulation rate leads to a smaller bubble density (fewer, but larger bubbles).

[75] 4. The blue ice emerging in the Allan Hills has a range of ages, and a corresponding range of depths through which it has traveled [Whillans and Cassidy, 1983, Figure 3]. Much of the ice has been exposed to pressures so great that each air bubble became dissolved in the ice to form a clathrate crystal [Price, 1995], and then reformed as the pressure was released [Lipenkov, 2000]. The sublimating sea glacier ice on Snowball Earth probably does not travel so deeply, reaching a maximum depth of no more than $150 \mathrm{~m}$ [Goodman, 2006, Figure 2f], so that much of it may resemble firn more than ice. (In Goodman's model, most of the sea glacier thickness is marine ice that accretes to the base at high latitude and melts off the base at low latitude, but this marine ice does not outcrop.) Our measurements at the upstream end of the blue ice region, examining the firn-to-ice transition on the surface, are therefore particularly relevant.

[76] 5. Cracks might have been less prevalent on the sea glacier, because of a smaller seasonal cycle on the tropical ocean than in Antarctica. This topic is discussed in the next section.

[77] Items (1), (2), and (4) would tend to make the scattering coefficient of sea glacier ice larger than that of Antarctic blue ice areas today, but items (3) and (5) would have the opposite effect.

\subsection{Cracks and Bubbles on the Snowball Ocean: Were They Similar to Those of the Allan Hills?}

[78] Cracks are ubiquitous in the surface ice in the Allan Hills, but to what extent would cracks have formed on the tropical ocean? The cracks in Allan Hills ice are due to temperature cycles, both seasonal and diurnal. The tropical and subtropical ocean would have had a more muted seasonal cycle but probably a larger diurnal cycle. This would affect not only the cracks, but also the bubble shapes, which we think will be more complicated and less spherical in the presence of temperature fluctuations, due to temperature gradient-induced air bubble migration [Dadic et al., 2010].

[79] The diurnal range of surface temperature in January on the East Antarctic Plateau at latitude $75^{\circ} \mathrm{S}$ is $13 \mathrm{~K}$ [Hudson and Brandt, 2005, Figure 20], even though the diurnal cycle of solar irradiance is muted relative to the equator. There is geologic evidence that the diurnal temperature cycling on Snowball Earth was large enough to form cracks in equatorial permafrost. This evidence comes from fossil sand-wedges in Neoproterozoic permafrost close to the paleoequator [Maloof et al., 2002].
[80] None of this evidence allows us to quantify the SSA of cracks on the snowball ocean. If there are plenty of bubbles, then the addition of cracks does not increase the albedo by much, as shown in Table 2, so it may not be important to quantify the relevance of Allan Hills cracks to cracking on the snowball ocean. However, many of the bubbles in the surface ice of the Allan Hills apparently originated from cracks, so it may be useful to estimate a minimum SSA from bubbles that would result if cracking and temperature gradient air bubble migration were entirely absent. That is what we will do next, in the following paragraphs.

[81] Since it is unlikely that meteoric glacier ice on Snowball Earth traveled deep enough for the bubbles to dissolve as clathrate crystals, we can use the measured bubble counts at closeoff to get a minimum expected SSA for when the bubbly ice rises to the surface in the zone of net sublimation.

[82] Let $f_{i}$ be the fraction of bubbles in size-bin $i$, so that

$$
f_{i}=\frac{n_{i}}{n_{0}},
$$

where $n_{i}$ is the number density of bubbles in size-bin $i$ and $n_{0}$ is the total number density of bubbles. Then, in a unit volume, the ratio of bubble area to bubble volume, $A_{b} / V_{b}$, is

$$
\frac{A_{b}}{V_{b}}=\frac{n_{0} \sum_{i} 4 \pi r_{i}^{2} f_{i}}{n_{0} \sum_{i} \frac{4}{3} \pi r_{i}^{3} f_{i}}=\frac{3 \sum_{i} r_{i}^{2} f_{i}}{\sum_{i} r_{i}^{3} f_{i}},
$$

and the specific surface area is

$$
\alpha=\frac{A_{b}}{V_{b}}\left(\frac{1}{\rho}-\frac{1}{\rho_{\text {ice }}}\right) .
$$

The size distribution of bubbles in the Vostok ice core is plotted in Figure 3 of Lipenkov [2000]. Digitizing that plot gives us $f_{i}$ at a depth of $183 \mathrm{~m}$, where the pressure is 17 bar. At closeoff, the bubbles would have been at the atmospheric pressure for the surface of Vostok, 0.62 bar, so the bubble radii would be expected to be larger by the factor $(17 / 0.62)^{1 / 3}=3.0$. Lipenkov's Figure 2 shows that the bubbles at closeoff are actually larger only by the factor 2.24 , so we will shift the plotted size distribution by that factor. The size distribution at closeoff $\left(\rho=830 \mathrm{~kg} / \mathrm{m}^{3}\right)$ then gives $A_{b} / V_{b}=7085 \mathrm{~m}^{-1}$, with an effective bubble radius of $\mathrm{r}=423 \mu \mathrm{m}$. Using the ice density of $890 \mathrm{~kg} / \mathrm{m}^{3}$, as measured on the surface in the Allan Hills, the effective bubble radius shrinks to $\mathrm{r}=286 \mu \mathrm{m}$ and $A_{b} / V_{b}=10480 \mathrm{~m}^{-1}$. With this, we obtain the minimum SSA for bubbly ice raising to the surface of $\alpha=0.35 \mathrm{~m}^{2} / \mathrm{kg}$.

[83] The SSA of blue ice from $10 \mathrm{~m}$ depth was $0.16 \mathrm{~m}^{2} / \mathrm{kg}$. This value was obtained from micro-CT, and it is lower than any of our other samples. At $10 \mathrm{~m}$ depth, the total pressure is the weight of the ice plus atmospheric pressure of 0.8 bar, a total of 1.7 bars. Assuming the bubbles would expand with release of pressure, this ice should have $\alpha=0.16(1.7 / 0.8)^{2 / 3}=0.26 \mathrm{~m}^{2} / \mathrm{kg}$ when it reaches the surface. This is $\sim 20 \%$ smaller than the smallest value we measured from micro-CT of a surface sample of blue ice (R1, $\alpha=0.32 \mathrm{~m}^{2} / \mathrm{kg}$ ). This is not surprising when we consider the difference between the surface samples, which were exposed to seasonal/daily temperature cycles (e.g., Figure 9d) and 
the $10 \mathrm{~m}$ deep ice sample, which was not affected by shortterm temperature cycles (e.g., Figure 9e). The SSA of 0.26 is $\sim 25 \%$ smaller than our estimate of bubble SSA using the calculation above that was based on the Lipenkov [2000] bubble size distribution, $\alpha=0.35 \mathrm{~m}^{2} / \mathrm{kg}$. The Allan Hills ice probably did go through a clathrate phase, and the bubbles reforming from clathrate may have smaller SSA than the original bubbles. But even if we do use $\alpha=0.26 \mathrm{~m}^{2} / \mathrm{kg}$ in our radiative transfer model, we obtain the not-insignificant albedos of 0.48 for Snowball Earth clear-sky conditions and 0.58 for cloudy sky at present Allan Hills conditions.

[84] In summary, there are significant uncertainties, but we do recommend our results from Allan Hills for use in climate modeling of Snowball Earth. Figure 19 and equation (8) will give the albedo for pure snow, firn, or ice, and then, Figure 18 can be used to estimate the reduction of albedo by a specified mixing ratio of volcanic ash (or other impurities, with mixing ratio scaled by their relative mass-absorption cross sections).

\section{Summary}

[85] Here we list the key messages of this paper.

[86] 1. Sublimation areas of the East Antarctic Ice Sheet can represent the variety of ice surfaces expected on cold tropical sea glaciers: snow, firn, young ice, and old ice.

[87] 2. Specific surface area (SSA) of ice, firn, and snow samples was measured by microcomputed tomography.

[88] 3. Both cracks and bubbles contribute to ice albedo. Cracks may be produced by seasonal and diurnal temperature cycling, and by expansion of bubbles as they are carried upward. The albedo from bubbles alone (or cracks alone) is nearly as high as the albedo from bubbles plus cracks.

[89] 4. Bubbles may change shape when exposed to alternating temperature gradients through temperature cycling. This change in shape can increase the SSA and the albedo of ice. The estimated increase in SSA from our samples was $\sim 40 \%$ (from $\alpha=0.26 \mathrm{~m}^{2} / \mathrm{kg}$ to $\alpha=0.32 \mathrm{~m}^{2} / \mathrm{kg}$ ). This causes a change in albedo of +0.02 .

[90] 5. UV-blue albedo is reduced by volcanic ash in the ice.

[91] 6. Radiative transfer modeling can explain the albedo spectra, using SSAs for ice/air interfaces larger than those measured by micro-CT.

[92] 7. Broadband albedos for Allan Hills clear-sky conditions are $0.57-0.80$; higher under cloudy sky. They may be parameterized as a function of density. The broadband albedos for blue ice in the Allan Hills are in the range previously reported for other Antarctic locations, and in the range that favors sea glaciers hundreds of meters thick over the tropical ocean in climate models of Snowball Earth [Warren et al., 2002; Warren and Brandt, 2006; Goodman, 2006; Li and Pierrehumbert, 2011].

[93] 8. In this paper, we have not limited ourselves to presenting measured spectral albedos; we have also attempted to explain them. We think this is valuable for the application of Antarctic blue ice albedos to represent the tropical ocean. One could simply measure the albedos and recommend their use for snowball modeling. But those albedos are affected by the volcanic ash so would be inappropriate to represent uncontaminated sea glaciers. With the radiation modeling, we are able to remove the effect of the ash and present albe- dos for both clean and contaminated ice; both types may exist on Snowball Earth. Furthermore, understanding the fundamental properties of ice that influence the albedo will allow climate-modeling efforts to apply appropriate albedos even for ice conditions that may not have been measured and may not exist in nature on the modern Earth.

[94] Acknowledgments. We thank John Schutt and Andrei Kurbatov for advice on locating our field camp. In the field, we benefited from the experience of the Kurbatov group, whose camp was nearby, and they provided an ice sample from $10 \mathrm{~m}$ depth for our analysis. Melanie Fitzpatrick organized the logistics, and both she and Regina Carns participated in the fieldwork and discussions about the measurements. Logistical support by the U.S. Antarctic Program was excellent. We thank Sarah Doherty for measuring the absorption spectrum of the volcanic ash samples, Dean Hegg for instructions on the use of his electrobalance for weighing the filters, Matthias Jaggi and Margret Matzl for their help with the micro-CT measurements and data evaluation, Fabienne Riche for her help with stereology and Huw Horgan for numerous discussions about bubbles. This research was supported by U.S. NSF grants ANT-07-39779 and ANT-11-42963. Ruzica Dadic was supported by a postdoctoral fellowship from the Swiss National Science Foundation (Project 124273).

\section{References}

Abbot, D. S., A. Voigt, and D. Koll (2011), The Jormungand global climate state and implications for Neoproterozoic glaciations, J. Geophys. Res., 116, D18103, doi:10.1029/2011JD015927.

Alley, R. B., J. H. Perepezko, and C. R. Bentley (1986), Grain growth in polar ice: II Application, J. Glaciol., 32(112), 425-433.

Arnaud, L., V. Ya. Lipenkov, J. M. Barnola, M. Gay, and P. Duval (1998), Modelling of the densification of polar firn: Characterization of the snowfirn transition, J. Glaciol., 26, 39-44.

Arnaud, L., J. M. Barnola, and P. Duval (2000), Physical modelling of the densification of snow/firn and ice in the upper part of polar ice sheets, in Physics of Ice Core Records, edited by T. Hondoh, pp. 285-305, Hokkaido Univ. Press, Sapporo, Japan.

Baddeley, A. J., H. J. Gundersen, and L. M. Cruz-Orive (1986), Estimation of surface area from vertical sections, J. Microsc., 142, 259-76.

Bindschadler, R., P. Vornberger, A. Fleming, A. Fox, J. Mullings, D. Binnie, S. Paulsen, B. Granneman, and D. Gorodetzky (2008), The LANDSAT mosaic image of Antarctica, P. Soc. Photo-opt. Ins., 112 (12), 4214-4226. Bintanja, R. (1999), On the glaciological meteorological and climatological significance of Antarctic blue ice areas, Rev. Geophys., 37(3), 337-359.

Bintanja, R., and M. R. van den Broeke (1995), The surface energy balance of Antarctic snow and blue ice, J. Appl. Meteorol., 34, 337-359.

Bohren, C. F. (1983), Colors of snow, frozen waterfalls, and icebergs, $J$. Opt. Soc Am., 73(12), 1646-1652.

Brandt, R. E., and S. G. Warren (1993), Solar heating rates and temperature profiles in Antarctic snow and ice, J. Glaciol., 39, 99-110.

Brandt, R. E., S. G. Warren, and A. D. Clarke (2011), A controlled snowmaking experiment testing the relation between black carbon content and reduction of snow albedo, J. Geophys. Res., 116, D08109, doi:10.1029/2010JD015330.

Budyko, M. I. (1969), The effect of solar radiation variations on the climate of the Earth, Tellus, 21, 611-619.

Cassidy, W. A., R. P. Harvey, J. Schutt, G. Delisle, and K. Yanai (1992), The meteorite collection sites of Antarctica, Meteoritics, 27, 490-525.

Chandler, M., and L. Sohl (2000), Climate forcings and the initiation of low-latitude ice sheets during neoproterozoic varanger glacial interval, $J$. Geophys. Res., 105, 20,737-20,756.

Dadic, R., B. Light, and S. G. Warren (2010), Migration of air bubbles in ice under a temperature gradient, with application to "Snowball Earth", J. Geophys. Res., 115, D18125, doi:10.1029/2010JD014148.

Doherty, S. J., S. G. Warren, T. C. Grenfell, A. D. Clarke, and R. E. Brandt (2010), Light-absorbing impurities in Arctic snow, Atmos. Chem. Phys., $10,11,647-11,680$

Evans, D. A. D. (2000), Stratigraphic, geochronological, and paleomagnetic constraints upon the neoproterozoic climatic paradox, American Journal of Science, 300(5), 347-433.

Faure, G., and D. Buchanan (1991), Ablation rates of the ice fields in the vicinity of the Allan Hills, Victoria Land, Antarctica, Antar. Res. S., 53, 19-31.

Flanner, M. G., and C. S. Zender (2006), Linking snowpack microphysics and albedo evolution, J. Geophys. Res., 111, D12208, doi: $10.1029 / 2005$ JD006834.

Gold, L. W. (1963), Crack formation in ice plates by thermal shock, Can J. Phys., 41 (10), 1712-1728, doi:10.1139/p63-172. 
Goodman, J. C. (2006), Through thick and thin: Marine and meteoric ice in a "Snowball Earth" climate, Geophys. Res. Lett., 33(L16701), doi:10.1029/2006GL026840.

Goodman, J. C., and R. T. Pierrehumbert (2003), Glacial flow of floating marine ice in Snowball Earth, J. Geophys. Res., 108(C10), 3308, doi:10.1029/2002JC001471.

Gow, A. J. (1969), On the rates of growth of grains and crystals in South Polar firn, J. Glaciol., 8, 241-252.

Gow, A. J. (1970), Deep core studies of the crystal structure and fabrics of Antarctic glacier ice, Research Report 282, CRREL, USA.

Grenfell, T. C., and S. G. Warren (1999), Representation of a nonspherical ice particle by a collection of independent spheres for scattering and absorption of radiation, J. Geophys. Res., 104(D24), 31,697-31,709.

Grenfell, T. C., S. G. Warren, and P. C. Mullen (1994), Reflection of solar radiation by the Antarctic snow surface at ultraviolet, visible, and nearinfrared wavelengths, J. Geophys. Res., 99, 18,669-18,684.

Grenfell, T. C., S. P. Neshyba, and S. G. Warren (2005), Representation of a nonspherical ice particle by a collection of independent spheres for scattering and absorption of radiation: 3 . Hollow columns and plates, $J$. Geophys. Res., 110, D17203, doi:10.1029/2005JD005811.

Grenfell, T. C., S. J. Doherty, A. D. Clarke, and S. G. Warren (2011), Light absorption from particulate impurities in snow and ice determined by spectrophotometric analysis of filters, Appl. Optics., 50, 2037-2048.

Harland, W. B. (1964), Critical evidence for a great infra-Cambrian glaciation, Geol. Rundsch., 54, 45-61.

Harvey, R. P., N. W. Dunbar, W. C. McIntosh, R. P. Esser, K. Nishiizumi, S. Taylor, and M. W. Caffee (1998), Meteoritic event recorded in Antarctic ice, Geology, 26, 607-610.

Haussener, S., M. Gergely, M. Schneebeli, and A. Steinfeld (2012), Determination of the macroscopic optical properties of snow based on exact morphology and direct pore-level heat transfer modeling, J. Geophys. Res., 117, doi:10.1029/2012JF002332.

Herron, M. M., and C. C. Langway (1980), Firn densification: An empirical model, J. Glaciol., 25, 373-385.

Hildebrand, T., and P. Rüegsegger (1997), A new method for the modelindependent assessment of thickness in three-dimensional images, $J$. Microsc., 185(1), 67-75, doi:10.1046/j.1365-2818.1997.1340694.x.

Hoffman, P. F., and D. P. Schrag (2002), The snowball Earth hypothesis: Testing the limits of global change, Terra Nova, 14, 129-155.

Hudson, S. R., and R. E. Brandt (2005), A look at the surface-based temperature inversion on the Antarctic Plateau, J. Climate., 18, 1973-1696, doi:http://dx.doi.org/10.1175/JCLI3360.1.

Hudson, S. R., S. G. Warren, R. E. Brandt, T. C. Grenfell, and D. Six (2006), Spectral bidirectional reflectance of Antarctic snow: Measurements and parameterization, J. Geophys. Res., 111, D18106, doi:10.1029/2006JD007290.

Hyde, W. R., T. J. Crowley, S. K. Baum, and W. R. Peltier (2000), Neoproterozoic 'snowball earth' simulations with a coupled climate/ice-sheet model, Nature, 405, 425-429.

Joseph, J. H., W. J. Wiscombe, and J. A. Weinman (1976), The deltaEddington approximation for radiative flux transfer, J. Atmos. Sci., 33, 2452-2459.

Kaempfer, T. U., and M. Schneebeli (2007), Observation of isothermal metamorphism of new snow and interpretation as a sintering process, $J$. Geophys. Res., 112, D24101, doi:10.1029/2007JD009047.

Kerbrat, M., B. Pinzer, T. Huthwelker, H. W. Gäggeler, M. Ammann, and M. Schneebeli (2008), Measuring the specific surface area of snow with $\mathrm{X}$-ray tomography and gas adsorption: Comparison and implications for surface smoothness, Atmos. Chem. Phys., 8, 1261-1275.

Kindel, B. C., Z. Qu, and A. F. H. Goetz (2001), Direct solar spectral irradiance and transmittance measurements from 350-2500 nm, Appl. Optics., 40, 3483-3494, doi:10.1364/AO.40.003483.

Kipfstuhl, S., S. H. Fariam, N. Azuma, J. Freitag, I. Hamann, P. Kaufmann, H. Miller, K. Weiler, and F. Wilhelms (2009), Evidence of dynamic recrystallization in polar firn, J. Geophys. Res., 114, doi:10.1029/2008JB005583.

Kirschvink, J. L. (1992), Late Proterozoic low-latitude global glaciation: The snowball Earth, in The Proterozoic Biosphere, edited by Schopf, J. W., and C. Klein, Cambridge Univ. Press, New York, 51-52.

Kirschvink, J. L., E. J. Gaidos, L. E. Bertani, N. J. Beukes, J. Gutzmer, L. N. Maepa, and R. E. Steinberger (2000), Paleoproterozoic snowball Earth: Extreme climatic and geochemical global change and its biological consequences, Proc. Nat. Acad. Sci. USA, 97, 1400-1405.

LaChapelle, E. R. (1969), Field Guide to Snow Crystals, University of Washington Press.

Lewis, J. P., A. J. Weaver, and M. Eby (2006), Deglaciating the snowball Earth: Sensitivity to surface albedo, Geophys. Res. Lett., 33, L23604, doi:10.1029/2006GL027774.
Li, D., and R. T. Pierrehumbert (2011), Sea glacier flow and dust transport on Snowball Earth, Geophys. Res. Lett., 38, L17501, doi:10.1029/2011GL048991.

Light, B., R. E. Brandt, and S. G. Warren (2009), Hydrohalite in cold sea ice: Laboratory observations of single crystals, surface accumulations, and migration rates under a temperature gradient, with application to "Snowball Earth", J. Geophys. Res., 114, C07018, doi:10.1029/2008JC005211.

Lipenkov, V. Ya. (2000), Air bubbles and air-hydrate crystals in the Vostok ice core, in Physics of Ice Core Records, edited by Hondoh, T., Hokkaido University Press, Sapporo, Japan, 327-358.

Liston, G., and J.-G. Winther (2005), Antarctic surface and subsurface snow and ice melt fluxes, J. Climate., 18, 1469-1481.

Liston, G., J.-G. Winther, O. Bruland, H. Elvehøy, and K. Sand (1999), Below-surface ice melt on the coastal Antarctic ice sheet, J. Glaciol., 45, 273-285.

Maloof, A. C., J. B. Kellogg, and A. M. Anders (2002), Neoproterozoic sand wedges: Crack formation in frozen soils under diurnal forcing during a snowball Earth, Earth. Planet. Sc. Lett., 204, 1-15.

Martinerie, P., V. Ya. Lipenkov, D. Raynaud, J. Chapellaz, N. I. Barkov, and C. Lorius (1994), Air content paleo record in Vostok ice core (Antarctica): A mixed record of climatic and glaciological parameters, $J$. Geophys. Res., 99, 10,565-10,576.

Matzl, M., and M. Schneebeli (2010), Stereological measurement of the specific surface area of seasonal snow types: Comparison to other methods, and implications for mm-scale vertical profiling, Cold. Reg. Sci. Technol., 64, 1-8, doi:10.1016/j.coldregions.2010.06.006.

Micheels, A., and M. Montenari (2008), A snowball Earth versus a slushball Earth: Results from the neoproterozoic climate modeling sensitivity experiments, Geosphere, 4, 401-410.

Mullen, P. C., and S. G. Warren (1988), Theory of the optical properties of lake ice, J. Geophys. Res., 93, 8403-8414.

Nakaya, U. (1956), Properties of single ice crystals revealed by internal melting, Research Paper 13, US Army Corps of Engineers, Snow Ice and Permafrost Establishment.

Neshyba, S. P., T. C. Grenfell, and S. G. Warren (2003), Representation of a nonspherical ice particle by a collection of independent spheres for scattering and absorption of radiation: II. Hexagonal columns and plates, J. Geophys. Res., 108, 4448, doi:10.1029/2002JD003302.

Nishio, F., and J. O. Annexstad (1980), Studies on the ice flow in the bare ice area near the Allan Hills in Victoria Land, Antarctica. Memoirs of the National Institute of Polar Research, Special issue 17, 1-13.

Nishio, F., N. Azuma, A. Higashi, and J. O. Annexstad (1982), Structural studies of bare ice near the Allan Hills, Victoria Land, Antarctica: A mechanism of meteorite concentration, Ann. Glaciol., 3, 222-226.

Nishio, F., T. Katsushima, and H. Ohmae (1985), Volcanic ash layers in bare ice areas near the Yamato Mountains, Dronning Maud Land and the Allan Hills, Victoria Land, Antarctica, Ann. Glaciol., 7, 34-40.

Painter, T., and J. Dozier (2004), Measurements of the hemisphericaldirectional reflectance of snow at fine spectral and angular resolution, $J$. Geophys. Res., 109, D18115, doi:10.1029/2003JD004458.

Pierrehumbert, R. T. (2005), Climate dynamics of a hard snowball Earth, $J$. Geophys. Res., 110, D01111, doi:10.1029/2004JD005162.

Pierrehumbert, R. T., D. S. Abbot, A. Voigt, and D. Koll (2011), Climate of the neoproterozoic, Ann. Rev. Earth Planet. Sci., 39, 417-460.

Pollard, D., and J. F. Kasting (2004), Climate-ice sheet simulations of neoproterozoic glaciation before and after collapse to snowball Earth, in The Extreme Proterozoic: Geology, Geochemistry, and Climate, Geophys. Monogr. Ser., edited by Jenkins, G. et al., vol. 146, AGU, Washington, D.C, 91-105.

Pollard, D., and J. F. Kasting (2005), Snowball Earth: A thin ice solution with flowing sea glaciers, J. Geophys. Res., 110, C07010, doi:10.1029/2005JC003411.

Pollard, D., and J. F. Kasting (2006), Reply to comment by Stephen G. Warren and Richard E. Brandt on "Snowball Earth: A thin-ice solution with flowing sea glaciers", J. Geophys. Res., 111, doi: $10.1029 / 2006 \mathrm{JC} 003488$.

Poulsen, C., and R. Jacob (2004), Factors that inhibit snowball Earth simulation, Paleoceanography, 19, PA4021, doi:10.1029/2004PA001056.

Price, P. B. (1995), Kinetics of conversion of air bubbles to air hydrate crystals in Antarctic ice, Science, 267, 1802-1804.

Reijmer, C. H., R. Bintanja, and W. Greuell (2001), Surface albedo measurements over snow and blue ice in thematic mapper bands 2 and 4 in Dronning Maud Land, Antarctica, J. Geophys. Res., 106, 9661-9672.

Riche, F., M. Schneebeli, and S. Tschanz (2012), Design-based stereology to quantify structural properties of artificial and natural snow using thin sections, Cold Regions Science and Technology, 79-80, 67-74, doi:10.1016/j.coldregions.2012.03.008. 


\section{DADIC ET AL.: ALBEDO OF BARE ICE IN ANTARCTICA}

Salamatin, A. N., V. Ya. Lipenkov, J. M. Barnola, A. Hori, P. Duval, and T. Hondoh (2009), Snow/firn densification in polar ice sheets, in Physics of Ice Core Records II, edited by Hondoh, T., Hokkaido Univ. Press, Sapporo, Japan, 195-222.

Sellers, W. D. (1969), A global climatic model based on the energy balance of the Earth-atmosphere system, J. Appl. Meteorol., 8, 392-400.

Shreve, R. L. (1967), Migration of bubbles, vapor figures, and brine pockets in ice under a temperature gradient, J. Geophys. Res., 72, 4093-4100.

Spaulding, N. E., V. B. Spikes, G. S. Hamilton, P. A. Mayewski, N. W. Dunbar, R. P. Harvey, J. Schutt, and A. V. Kurbatov (2012), Ice motion and mass balance at the Allan Hills blue ice area, Antarctica, with implications for paleoclimate reconstructions, J. Glaciol., 58(208), 399-406, doi:10.3189/2012JoG11J176.

Spencer, M. K., R. B. Alley, and T. T. Creyts (2001), Preliminary firn-densification model with 38-site dataset, J. Glaciol., 47(159), 671-676.

Spencer, M. K., R. B. Alley, and J. J. Fitzpatrick (2006), Developing a bubble number-density paleoclimatic indicator for ice, J. Glaciol., 52, 358-364.

Stehle, N. S. (1967), Migration of bubbles in ice under a temperature gradient, in Physics of Snow and Ice, Proc. Int. Conf. on Low Temp. Sci. Hokkaido Univ. Sapporo, edited by Oura, H., Bunyeido Printing Co., Sapporo, Japan, 219-232.

Stock, S. R. (2009), Microcomputed Topography: Methodology and Applications, CRC Press, Boca Raton, Florida.

Tschanz, S., P. Burri, and E. Weibel (2010), A simple tool for stereological assessment of digital images: The STEPanizer, J. Microsc., 243(1), 47-59.

Warren, S. G. (1982), Optical properties of snow, Rev. Geophys. Space. Phys., 20(1), 67-89.
Warren, S. G., and R. E. Brandt (2006), Comment on "Snowball Earth: A thin ice solution with flowing sea glaciers" by David Pollard and James F. Kasting, J. Geophys. Res., 111(C09016), doi:10.1029/ 2005JC003411.

Warren, S. G., and R. E. Brandt (2008), Optical constants of ice from the ultraviolet to the microwave: A revised compilation, J. Geophys. Res., 113(D14220), doi:10.1029/2007/JD009744.

Warren, S. G., and M. S. Town (2011), Antarctica, in Encyclopedia of Climate and Weather, pp. 63-71, Oxford Univ. Press, New York.

Warren, S. G., T. C. Grenfell, and P. C. Mullen (1986), Optical properties of Antarctic snow, Antarct. J. US., 21, 247-248.

Warren, S. G., R. E. Brandt, and R. D. Boime (1993), Blue ice and green ice, Antarct. J. US., 28, 255-256.

Warren, S. G., R. E. Brandt, T. C. Grenfell, and C. P. McKay (2002), Snowball Earth: Ice thickness on the tropical ocean, J. Geophys. Res., 107(C10), 3167, doi:10.1029/2001JC001123.

Warren, S. G., R. E. Brandt, and T. C. Grenfell (2006), Visible and near-ultraviolet absorption spectrum of ice from transmission of solar radiation into snow, Appl. Optics., 45, 5320-5334.

Weller, G. E. (1968), The heat budget and heat transfer processes in Antarctic plateau ice and sea ice, ANARE Scientific Reports 102, Australian Antarctic Division, Kingston, Tasmania, Australia.

Whillans, I. M., and W. A. Cassidy (1983), Catch a falling star: Meteorites and old ice, Science, 222, 55-57.

Wiscombe, W. J., and S. G. Warren (1980), A model for the spectral albedo of snow. I: Pure snow, J. Atmos. Sci., 37 2712-2733.

Wiscombe, W. J., R. M. Welch, and W. D. Hall (1984), The effects of very large drops on cloud absorption, Part I, Parcel models, J. Atmos. Sci., 41, $1336-1355$ 